\title{
IMPROVEMENT OF DRUG SAFETY BY THE USE OF LIPID-BASED NANOCARRIERS
}

\author{
Sok Bee Lim ${ }^{1}$, Amrita Banerjee ${ }^{1}$ and Hayat Önyüksel ${ }^{1,2}$
}

${ }^{1}$ Departments of Biopharmaceutical Sciences, ${ }^{2}$ Bioengineering, University of Illinois at Chicago, Chicago, Illinois 60612

Address for correspondence: Hayat Önyüksel

Department of Biopharmaceutical Sciences (M/C 865), College of Pharmacy

University of Illinois at Chicago

833 South Wood Street

Chicago, Illinois 60612-7231

U.S.A.

Phone: $312-996-2097$

Fax: 312-996-0098

E-mail: hayat@uic.edu 


\begin{abstract}
Drug toxicity is an important factor that contributes significantly to adverse drug events in current healthcare practice. Application of lipid-based nanocarriers in drug formulation is one approach to improve drug safety. Lipid-based delivery systems include micelles, liposomes, solid lipid nanoparticles, nanoemulsions and nanosuspensions. These carriers are generally composed of physiological lipids welltolerated by human body. Delivery of water-insoluble drugs in these formulations increases their solubility and stability in aqueous media and eliminates the need for toxic co-solvents or $\mathrm{pH}$ adjustment to solubilize hydrophobic drugs. Association or encapsulation of peptides/proteins within lipid-based carriers protects the labile biologics against enzymatic degradation, hence reducing the therapeutic dose required and risk of dose-dependent toxicity. Most importantly, lipid-based nanocarriers alter the pharmacokinetics and biodistribution of drugs through passive and active targeting, leading to increased drug accumulation at target sites while significantly decreasing non-specific distribution to other tissues. Furthermore, surface modification of these nanocarriers reduces immunogenicity of drug-carrier complexes, imparts stealth by preventing opsonization and removal by phagocytes and minimizes interaction with circulating blood components. In view of heightening attention on drug safety in patient treatment, lipid-based nanocarrier is therefore an important and promising option for formulation of pharmaceutical products to improve treatment safety and efficacy.
\end{abstract}

Keywords: Lipid nanocarriers, drug safety, micelles, liposomes, solid lipid nanoparticle

\title{
Introduction
}

In drug discovery pipeline, it was estimated that approximately 10,000 chemical entities need to be tested before one would eventually reach the consumer market. Even at the phase III clinical trial testing stage, a tremendously high attrition rate $(42 \%)$ had been reported for drug candidates between 1990 - 2002. A major reason for this high failure rate has been attributed to drug toxicity, accounting for one third of the cases [1]. Furthermore, many United States Food and Drug Administration (USFDA) approved drugs have serious side effects in the general patient population [2, 3]. The severity of these adverse events could at times necessitate withdrawal of the pharmaceutical product. A classical example is the cyclooxygenase 2 inhibitor, rofecoxib (Vioxx ${ }^{\circledR}$ ), approved by FDA in 1999 for the treatment of osteoarthritis, acute pain and dysmenorrhoea. This drug was removed from market in year 2004 due to an unacceptable increased risk of cardiovascular side effects that included myocardial infarction, stroke and arrhythmia [4]. Studies have found that nearly $3 \%$ of the drug products approved between 1975 and 1999 were ultimately withdrawn from use. From 2000 to 2006, six major pharmaceutical products were pulled from the market due to safety concerns [5]. Since 1998, the number of serious adverse drug events reported to FDA has been on a continual rise over the years. In 2005, around 90,000 incidences of adverse drug effects were reported, out of which 15,000 were fatal [6]. It is henceforth without question that drug-related toxicity constitutes a major healthcare problem that warrants our close attention and prompt action. 
Toxicity of a pharmaceutical product is usually due to the active drug component, and in some cases the vehicle can contribute to the overall toxicity. Any drug that is used to exert a therapeutic action is also capable of producing undesirable, sometimes potentially fatal adverse effect. The narrower the therapeutic index of the drug, higher the risk of toxicity. This risk of toxicity is further exacerbated by the non-specific nature of drug biodistribution in systemic circulation with conventional formulations [7]. For example, the non-specific biodistribution and uptake of doxorubicin (Adriamycin ${ }^{\circledR}$ ) into heart tissues lead to accelerated myofilament degradation, inhibition of cardiac enzymes and myocardial cell death. Consequently, the cumulative doxorubicin dose allowable in patient for cancer treatment is restricted to minimize irreversible cardiotoxicity [8]. Lipid based formulation of doxorubicin (Doxil ${ }^{\circledR} / \mathrm{Caelyx}^{\circledR}$ ) reduces the cardiotoxicity of doxorubicin as described in the passive targeting section of this paper. Likewise, for many anticancer chemotherapy, non-specific in vivo distribution often results in significant drug accumulation in bone marrow which leads to severe myelosuppression, another common dose-limiting toxicity for this class of medication [9, 10]. Correspondingly, strict dosing regimens with stipulated drug-free intervals are enforced to allow recovery of the haemopoietic bone marrow cells before subsequent dose administration $[11,12]$. However, on the other hand, such dosing restrictions may potentially compromise and limit anti-tumor efficacy and cause drug resistance. To overcome resistance, with non targeted delivery, higher drug doses are needed to achieve the desired therapeutic effects, which in turn further increases overall systemic drug exposure and toxicity to normal healthy tissues [7]. Later in this review we will illustrate how lipid based nanocarriers can overcome drug resistance and provide targeted drug delivery.

Other than the active pharmaceutical ingredients, the excipients used in drug formulations could at times further contribute to additional side effects. The first commercial preparation of paclitaxel, Taxol ${ }^{\circledR}$, is a well-known example. To solubilize this water-insoluble drug, commercial preparation of paclitaxel $\left(\right.$ Taxol $\left.^{\circledR}\right)$ uses Cremophor $\mathrm{EL}^{\circledR}$, a polyoxyethylated castor oil vehicle, and dehydrated ethanol USP $(1: 1, \mathrm{v} / \mathrm{v})$ as its solvent system. This cosolvent has been associated with a high incidence of acute hypersensitivity reactions, characterized by respiratory distress, hypertension and angioedema. In an attempt to address these problems, an alternative preparation of paclitaxel, Abraxane ${ }^{\circledR}$ has been developed which uses albumin instead of Cremophor $\mathrm{EL}^{\circledR}$-based vehicle in its formulation and eliminates vehicle related toxicities. However, increased occurrence of sensory neuropathy has been documented with Abraxane ${ }^{\circledR}$ use [13]. Therefore it is evident that further improvement is still needed for reduced drugrelated toxicity and enhanced drug efficacy.

Polysorbate, a class of non-ionic surfactant commonly employed as pharmaceutical excipient to solubilize hydrophobic drugs, has also been associated with various adverse reactions. When used to formulate docetaxel, a water-insoluble cytotoxic taxane drug analogous to paclitaxel, polysorbate 80 resulted in occurrence of acute hypersensitivity reactions similar to Cremophor $\mathrm{EL}^{\circledR}$ in $\mathrm{Taxol}^{\circledR}$ [14]. Furthermore, this surface active agent was postulated to be accountable, in part, for the fluid retention side effect observed with the use of this docetaxel formulation [15]. In another case, use of polysorbate 80 in Eprex ${ }^{\circledR}$, a recombinant human erythropoietin preparation, had also been associated with an upsurge in the incidence of antibody-mediated pure red cell 
aplasia (PRCA) that led to market recall of the product. It was widely speculated that polysorbate 80 increased immunogenicity of Eprex $^{\circledR}$ by interacting with leachates extracted from the uncoated rubber stopper of the prefilled syringes. Lower stability of the polysorbate-containing formulation to handling and transportation stress, resulting in increased susceptibility of erythropoietin to protein aggregation was another possible explanation given $[16,17]$. In the pharmaceutical industry, another common strategy applied to increase aqueous solubility of drugs, particularly acidic or basic drugs, is $\mathrm{pH}$ adjustment. While this approach helps to maximize drug solubilization in their salt forms, there is amplified risk of drug precipitation upon intravenous injection when formulation $\mathrm{pH}$ becomes increasingly different from physiological $\mathrm{pH}$, leading to injection phlebitis and decreased drug effect $[18,19]$.

Henceforth, with these examples, it is obvious that the excipients in a formulation contribute tremendously to the overall safety of a pharmaceutical product. Lipids, being of natural base and relatively safe, offer a good alternative for the formulation of waterinsoluble drugs.

The common lipid-based nanocarriers include liposomes, lipid micelles, solid lipid nanoparticles (SLN), nanoemulsions and nanosuspensions (Fig. 1). Liposomes are vesicles composed of phospholipid bilayers with an aqueous core [20, 21]. Depending on the manufacturing process, the resulting vesicles may be uni or multi-lamellar of varying sizes $(50-2000 \mathrm{~nm})$. Lipid micelles, on the other hand, are monolayer nanostructures (7-35nm) composed of polyethylene glycol (PEG) conjugated phospholipids or lysolipids that self-assemble spontaneously in aqueous media at lipid concentrations above their critical micelle concentrations (CMCs). The hydrophobic acyl chains of the lipid monomers form the micelle core while the polar head groups (with the attached PEG chains for PEGylated phospholipids) make up the outer hydrophilic corona. Of these two kinds of lipid, PEGylated phospholipids are much more commonly utilized to prepare lipid micelles for drug delivery purposes [22-24]. Solid lipid nanoparticles are nanosized particulate solid lipid matrices $(50-1000 \mathrm{~nm})$ dispersed within an aqueous medium. Depending on the type and concentration of lipid used, emulsifier may be added to increase physical stability of the system [21, 25]. Lipid-based nanoemulsions are dispersions of oil and water which typically possess a dispersed phase (nanosized droplets ranging between $100-500 \mathrm{~nm}$ ) distributed within a continuous phase that is stabilized by surfactants and co-surfactants at the oil/water interface. Thermodynamically stable nanoemulsion forms spontaneously with minimum mechanical energy required $[22,26]$. Lastly, lipid-based nanosuspensions are colloidal dispersions $(100-500 \mathrm{~nm})$ of submicron hydrophobic drug particles that are stabilized against self-aggregation by an outer coating of lipid-derived surfactants within an aqueous medium. To achieve low polydispersity, high energy expenditure is usually necessary to break up the drug particles into the desired submicron sizes [22, 27]. To give a more comprehensive overview, all lipid-based nanocarriers below 1000nm is included in our discussion (Table 1). It should be noted that nanomedicines that are between 10-100nm have superior advantage over bigger sized particles for passive targeting and tissue penetration. 
Table 1 Lipid-based nanocarriers for drug delivery

\begin{tabular}{|c|c|c|c|c|c|}
\hline $\begin{array}{l}\text { Lipid-based } \\
\text { nanocarrier systems }\end{array}$ & Advantages & Limitations & Examples of application & Stage of development & References \\
\hline Liposomes & $\begin{array}{l}\text { Allow association of } \\
\text { hydrophobic drugs in } \\
\text { lipid bilayers and } \\
\text { encapsulation of } \\
\text { hydrophilic drugs in } \\
\text { central aqueous } \\
\text { compartment }\end{array}$ & $\begin{array}{l}\text { Controlled conditions } \\
\text { are required for } \\
\text { reproducibility }\end{array}$ & $\begin{array}{l}\text { Doxorubicin } \\
\text { Amphotericin B } \\
\text { Paclitaxel }\end{array}$ & $\begin{array}{l}\text { Marketed } \\
\text { Marketed } \\
\text { Clinical trial }\end{array}$ & $\begin{array}{l}{[28]} \\
{[29]} \\
{[22,30]}\end{array}$ \\
\hline Lipid micelles & $\begin{array}{l}\text { Spontaneous } \\
\text { formation above } \\
\text { CMCs; } \\
\text { high reproducibility; } \\
\text { well defined particle } \\
\text { size }<50 \mathrm{~nm}\end{array}$ & $\begin{array}{l}\text { Limited to hydrophobic } \\
\text { drugs and amphiphilic } \\
\text { peptides ( } \sim 30 \text { amino } \\
\text { acids in length) }\end{array}$ & $\begin{array}{l}\text { Paclitaxel } \\
\text { Doxorubicin } \\
\text { Camptothecin } \\
\text { Vasoactive intestinal } \\
\text { peptide } \\
\text { Budesonide }\end{array}$ & $\begin{array}{l}\text { Preclinical } \\
\text { Preclinical } \\
\text { Preclinical } \\
\text { Preclinical } \\
\text { Preclinical }\end{array}$ & $\begin{array}{l}{[27]} \\
{[31]} \\
{[32]} \\
{[33]} \\
\\
{[34]}\end{array}$ \\
\hline $\begin{array}{l}\text { Solid lipid } \\
\text { nanoparticles (SLN) }\end{array}$ & $\begin{array}{l}\text { Slow degradation of } \\
\text { lipid matrices allows } \\
\text { extended drug } \\
\text { release profiles }\end{array}$ & $\begin{array}{l}\text { High pressure or } \\
\text { elevated temperature } \\
\text { required for preparation } \\
\text { of SLN; } \\
\text { surfactant may be } \\
\text { needed for stabilization }\end{array}$ & $\begin{array}{l}\text { Actarit } \\
\text { Etoposide } \\
\text { Gadolinium }\end{array}$ & $\begin{array}{l}\text { Preclinical } \\
\text { Preclinical } \\
\text { Preclinical }\end{array}$ & $\begin{array}{l}{[35]} \\
{[36]} \\
{[37]}\end{array}$ \\
\hline Nanoemulsion & $\begin{array}{l}\text { Spontaneous } \\
\text { formation; } \\
\text { high reproducibility }\end{array}$ & $\begin{array}{l}\text { High surfactant } \\
\text { concentration required; } \\
\text { limited choices of } \\
\text { biocompatible } \\
\text { surfactants }\end{array}$ & $\begin{array}{l}\text { Paclitaxel } \\
\text { Primaquine }\end{array}$ & $\begin{array}{l}\text { Marketed (Orphan } \\
\text { drug) } \\
\text { Preclinical }\end{array}$ & $\begin{array}{l}{[38]} \\
{[39]}\end{array}$ \\
\hline Nanosuspension & $\begin{array}{l}\text { Suitable for drugs } \\
\text { with poor aqueous } \\
\text { and organic solvent } \\
\text { solubility }\end{array}$ & $\begin{array}{l}\text { Surfactant required to } \\
\text { coat the surface of drug } \\
\text { nanocrystals for } \\
\text { stabilization; } \\
\text { limited choices of } \\
\text { biocompatible lipid- } \\
\text { based surfactants; } \\
\text { high energy required for } \\
\text { homogenization of } \\
\text { particles }\end{array}$ & $\begin{array}{l}\text { Busulfan } \\
\text { Clofazamine }\end{array}$ & $\begin{array}{l}\text { Clinical } \\
\text { Preclinical }\end{array}$ & $\begin{array}{l}{[40]} \\
{[41]}\end{array}$ \\
\hline
\end{tabular}


Figure 1

(a)

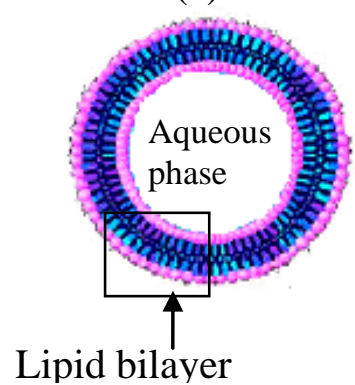
Hydrophobic

(b) core (c)

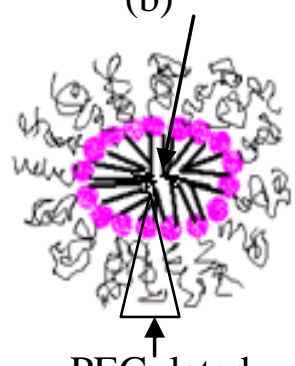

PEGylated

phospholipid

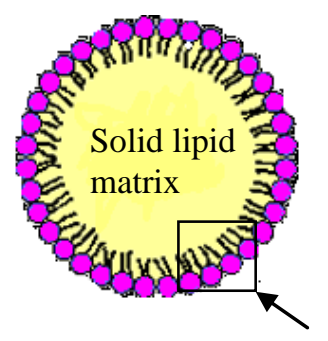

(d)

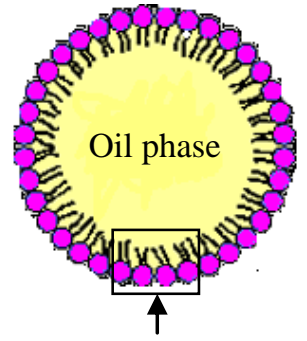

Phospholipid monolayer (e)

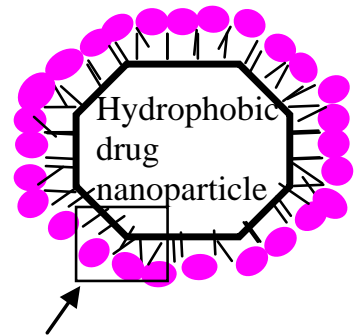

$$
\text { (1) }
$$

Lipid-based nanocarriers are generally composed of lipid components such as phospholipids, cholesterol and triglycerides [21, 42]. These materials are mostly extracted from or derivatized based on natural sources and are biocompatible, biodegradable in vivo. Many of these lipid excipients, such as phosphatidylcholine, 1,2distearoyl-sn-glycero-3-phosphoethanolamine- $N$-methoxy-poly(ethylene glycol 2000) (DSPE-PEG 2000 ) and cholesterol, have been used in FDA approved pharmaceutical products and have well-established safety profiles and toxicological data [43]. This is a major advantage over new investigational carriers such as polymeric particles (dendrimers, chitosan nanoparticles), carbon nanotubes, mixtures such as quantum dots and metals (gold and iron nanoparticles) [44-48].

However, although relatively safe, it should still be noted that lipids nonetheless exhibit dose-dependent toxicity when given at exceedingly high doses [49]. Excessive lipid intake may result in fat-overload syndrome characterized by hyperlipidemia, hepatosplenomegaly and gastrointestinal disorders [50]. For the purpose of drug formulation using lipid-based delivery systems, the quantity of lipid administered into human is significantly lower. Therefore, concern for lipid overdose will be low as long as the formulation is given within the recommended therapeutic dose range of the active ingredient.

Furthermore, other than dose, the type of lipid used is another important factor affecting toxicity. The positive charges on cationic lipids promote non-specific binding to circulating blood cells such as erythrocytes, lymphocytes as well as endothelial cells [51]. Cationic liposomes were found to induce greater activation of the human complement system compared to neutral liposomes [52]. Likewise, the presence of unprotected surface negative charges on lipid molecules such as phospatidylglycerol, phosphatidylserine serve as binding sites for plasma opsonin which favors uptake by macrophages [49]. Shielding of the nanocarrier surface charges by hydrophilic PEG is a common approach used to decrease immunogenicity of charged lipids [49]. A point to note here is that recent studies have indicated that PEG generates complement activation products in serum $[53,54]$. Antibodies against PEG that mediate clearance of PEG conjugated nanocarriers/particulates have also been reported [55]. This is more prominent for methoxy PEG (m-PEG) as compared to hydroxy PEG (OH-PEG). Therefore, based on this information, replacement of $m-P E G$ with OH-PEG may serve to ameliorate the concern of PEG based immunogencity and clearance of PEG based 
nanocarriers. Another point to consider is that the FDA approved and marketed liposomal formulation of doxorubicin $\left(\right.$ Doxil ${ }^{\circledR}$ ) utilizes $\mathrm{m}$-PEG as one of its constituents. We believe that the significance and extent of immunogenicity associated with PEG needs to be further investigated to obtain a clear safety profile of PEG. Currently approved liposomal products are composed of neutral lipids with or without PEGylated phospholipids [28]. Consequently, based on the physicochemical characteristics of the specific lipid in concern, the safety profile and maximum lipid dose allowable in pharmaceutical products will also vary.

When employed as surface active agents to stabilize nanoemulsion and nanosuspension, biocompatible amphiphilic lipid surfactants (e.g. PEGylated lipids, lecithin and its derivatives, medium chain triglycerides) are highly preferred compared to conventional synthetic ionic and non-ionic surfactants. Lipid surfactants act via formation of steric barriers to prevent droplet coalescence (nanoemulsion) or particle aggregation (nanosuspension) [26]. It is well known that many surfactants induce hemolysis when incubated with red blood cells. One mechanism cited involved the insertion of surfactant monomers into erythrocyte membrane bilayers leading to membrane integrity disruption, water uptake and osmotic cellular lysis [56, 57]. For this reason, lipid surfactants that have low CMCs and correspondingly low monomeric concentrations, may decrease risk of erythrocyte and other cellular lysis compared to conventional synthetic surface active agents. The CMC of DSPE-PEG $2000(0.5-1.0 \mu \mathrm{M})$, for example, is reported to be 100 folds lower than that of common ionic and non-ionic surface active agents [23, 24].

More recently, nanoparticulate self-assemblies of lipid surfactants in aqueous media received much attention as safe drug delivery systems. Nanomedicines prepared with lipid based drug delivery systems, after systemic administration, distribute differently in the body and interact differently with biological components at cellular/subcellular level compared to formulations of free drug molecules. Lipid nanocarriers can improve safety of product by solubilizing and stabilizing drug molecules, targeting them to the site of action and/ or changing the pharmacokinetics of drugs. In the following sections, we will provide insights into the different mechanisms by which nanosized lipid-based delivery systems can help improve drug safety for parenteral application.

\section{Safety improvement due to enhancement in solubility and stability of drugs by lipid nanocarriers}

Delivery of water-insoluble hydrophobic drugs

Approximately $40 \%$ of new chemical entities in pharmaceutical research pipelines exhibit poor aqueous solubility. Correspondingly, poorly water soluble drugs make up a significant portion of pharmaceutical drug sales over the world, estimated to amount $\$ 37$ billion [58]. In view of the hydrophobic nature of lipid-based delivery systems, they are therefore promising carriers for various water-insoluble drugs. When utilized as vehicles for hydrophobic drugs, the lipid-based nanocarriers encapsulate/solubilize the drug molecules and protect them from the surrounding aqueous environment. This will improve stability of the water-insoluble drugs in aqueous media and prevent drug precipitation both in vitro and in vivo. Since the formation and 
stability of these lipid-based colloidal systems are largely independent of solvent $\mathrm{pH}$, the formulations can be prepared at or near physiological $\mathrm{pH}$ to further eliminate drug toxicity associated with extreme $\mathrm{pH}$ adjustment [24].

The sterically stabilized phospholipid simple micelles (SSM), an example of lipid micelles, are attractive delivery systems for water-insoluble drugs. SSM are composed of the PEGylated phospholipid DSPE-PEG 2000 and each micelle has a central lipid core to allow effective solubilization of hydrophobic molecules [23,33]. With a low CMC in aqueous media [24], SSM are stable upon multiple-folds dilution after injection, thus ensuring the encapsulated drugs remains protected within micelles when circulating in blood stream. Using this lipid-based delivery platform, our laboratory has successfully achieved enhanced solubilization of different hydrophobic drugs for various therapeutic indications including cancer, rheumatoid arthritis and epilepsy [24, 27, 59, 60]. At a fixed lipid concentration of $5 \mathrm{mM}$, drug solubility in SSM was significantly improved by about 6 folds for diazepam, 30 folds for 17-(allylamino)-17-demethoxygeldanamycin (17-AAG) and 80 folds for indisulam, compared to their respective solubility in water. By increasing lipid concentration of SSM, further increase in drug solubilization capacity is possible. Our data showed similar or enhanced bioactivity of 17-AAG and indisulam in SSM compared to their respective free drugs in DMSO, indicating that SSM did not interfere with the intrinsic activity of the associated drug molecules [59,60]. SSM is noncytotoxic to cells upto $150 \mu \mathrm{M}$ lipid concentration which is a much higher concentration than that used for most cell bioassays (Fig. 2). In addition to SSM, our laboratory has also devised another novel lipid-based micellar platform: sterically stabilized mixed micelles (SSMM) composed of egg phosphatidylcholine (EPC) in addition to DSPE$P E G_{2000}$ [27]. The addition of hydrophobic EPC increased the hydrophobicity of the micellar core and the carrier capacity for the hydrophobic drug paclitaxel [27]. Similarly, formulation of mixed lipid micelles using d-alpha-tocopheryl polyethylene glycol 1000 succinate (TPGS) or vitamin E together with DSPE-PEG 2000 has also been reported by other research groups to augment hydrophobic drug solubilization capacity relative to SSM alone [61].

Figure 2

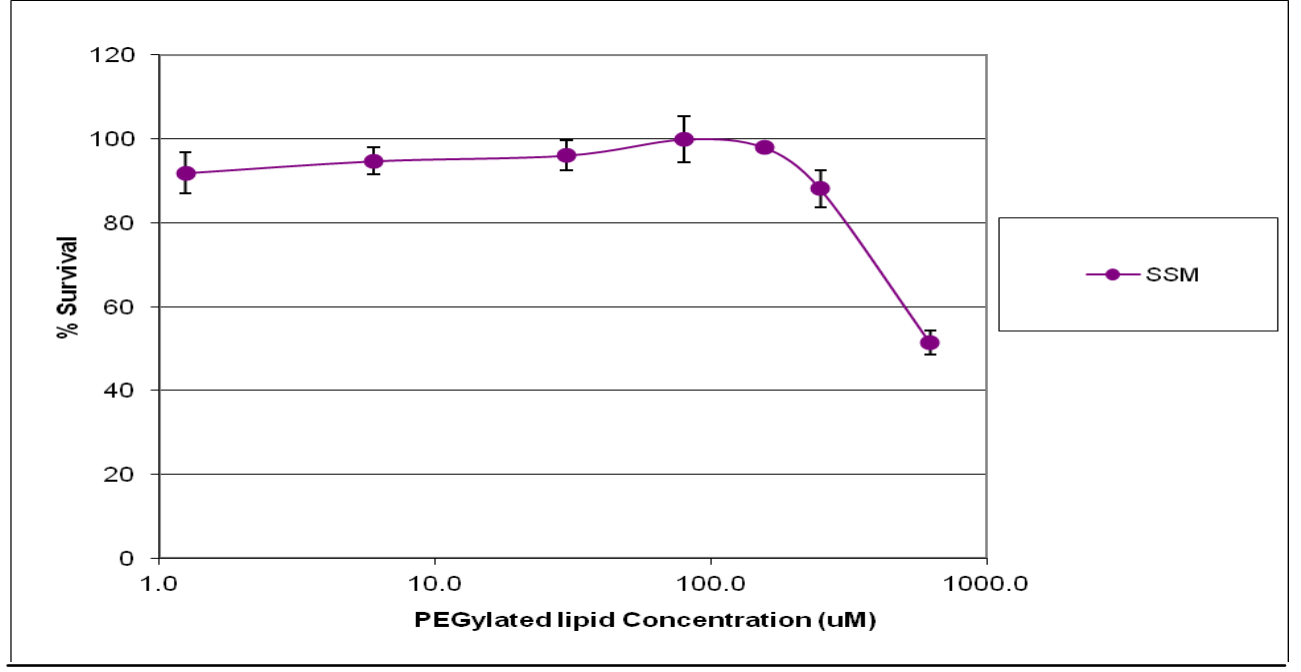


Liposome is another delivery system that has been commonly employed to improve aqueous solubilization of hydrophobic drugs [62]. The unique structure of liposomes allows dissolution of hydrophobic drug molecules within the acyl chain region of lipid bilayers. Multilamellar vesicles are useful for greater hydrophobic drug loading due to larger surface area of the lipid bilayers and for sustained drug release [21, 28]. Many hydrophobic drugs have been delivered using liposomes, such as indomethacin, amphotericin B, flavopiridol and azidothymidine, some of which have already reached the consumer market [29, 63, 64].

Solid lipid nanoparticles (SLN) either solubilize hydrophobic drug molecules homogeneously within the lipid matrix or form a drug-enriched shell around a central lipid core, or solubilize drug within the matrix core which is further enclosed by an outer shell [25, 42]. More recently, modifications of SLN have been undertaken to produce second generation SLN known as the nanostructured lipid carriers (NLC) and the lipid drug conjugates (LDC). NLC were introduced to increase drug loading capacity for hydrophobic drugs whereas LDC was the improved version of SLN for delivery of hydrophilic drugs. SLN have been investigated for the delivery of a broad range of hydrophobic drugs, including anticancer agents such as camptothecin and all-trans retinoic acid [65, 66], anti-rheumatic agent (actarit) [35], anti-parasitic agent (quinine) [67], and CNS-related disorders (clozapine) [68].

To deliver lipophilic drugs using nanoemulsions, drugs are added to the oil phase which forms nanodroplets (with isotropic oil core) dispersed within a continuous aqueous phase to give oil in water (o/w) nanoemulsions. The rate of drug release depends primarily on the oil/water partitioning coefficient of the drug molecules as well as the water content of the nanoemulsion system [69]. Nanoemulsion has been used as a carrier for lipophilic anticancer drugs such as tamoxifen and dacarbazine [70, 71]. One important consideration when formulating nanoemulsion lies in the selection of surfactants and co-surfactants as these are often needed in large quantities (3-20\%w/v) for product stabilization. Biocompatible surfactants are highly preferable to minimize any potential surfactant-induced toxicity [26].

Nanosuspensions allow high drug loading of an otherwise poorly soluble drugs in aqueous media [72]. In view of the tremendously huge hydrophobic surface area of the drug nanocrystals, large quantity of surfactants will therefore be necessary. Safe, lipid surfactant should be the preferred choice. Generally speaking, suitable drug candidates for nanosuspensions have high melting points and crystalline structure [22]. Nanosuspensions composed of lipophilic drug particles coated with PEGylated phospholipid monomers (sterically stabilized particles; $100-400 \mathrm{~nm}$ ) have also been observed in aqueous media when the added drug quantity exceed the solubilizing capacity of SSM or SSMM prepared using the co-precipitation/rehydration method [24, 27].

Besides the solubilization, lipid based carriers can also help to stabilize the water insoluble drugs. In our recent work we have clearly demonstrated the stability and solubility improvements of camptothecin in sterically stabilized micelles [32].

Delivery of peptide and protein drugs

Pharmaceutically active peptides and proteins often suffer from physical and/or chemical instability in vitro, rapid inactivation and elimination in vivo. As a result, for 
effective therapy, continuous intravenous infusion or frequent injections are usually required to sustain therapeutic plasma drug concentration at disease sites [25, 73]. However, prolonged infusion simultaneously leads to protracted drug exposure to other systemic organs, increasing risk of non-specific drug toxicity. Frequent parenteral injection is also a common cause of patient non-compliance. To overcome these problems, different lipid-based nanocarriers have been investigated as vehicles for labile peptide and protein drugs [21, 25, 74]. By protecting these therapeutic biomolecules within lipid carriers, their in vitro stability in aqueous media is improved to reduce aggregation and precipitation. When administered in vivo, peptides and proteins are shielded from enzymatic degradation, thereby increasing their duration of action which decreases the therapeutic dose required and corresponding dose-dependent adverse effects.

We have observed that various amphipathic peptide drugs undergo spontaneous association with SSM in aqueous media [20, 33, 75-79]. Peptides such as vasoactive intestinal peptide (VIP), glucagon-like peptide 1 (7-36) [GLP-1(7-36)] and gastric inhibitory peptides, associate most probably with the PEG region of PEGylated micelles, in view of the molecular net charge and relative hydrophilicity/hydrophobicity of these peptide candidates, rather than the more hydrophobic micelle cores as demonstrated in our previous fluorescence emission spectroscopic studies [76]. Micelles stabilize the associated peptides against physical aggregation and hydrolytic degradation in vitro to increase their shelf stability in aqueous media [33,79,80]. When administered in vivo, SSM protects the associated peptides from plasma enzymes inactivation, bringing about enhanced and significantly prolonged biological activities (Fig. 3) [33, 75, 77, 78]. Furthermore, specific peptide molecules undergo secondary conformational transition from random coil in aqueous media to show significantly increased $\alpha$ helicity in the presence of micelles. This is highly desirable for peptide drugs such as VIP, secretin and GLP-1(7-36) where the a helical structure has been reported to be the optimal conformation for binding to their specific receptors [20, 81].

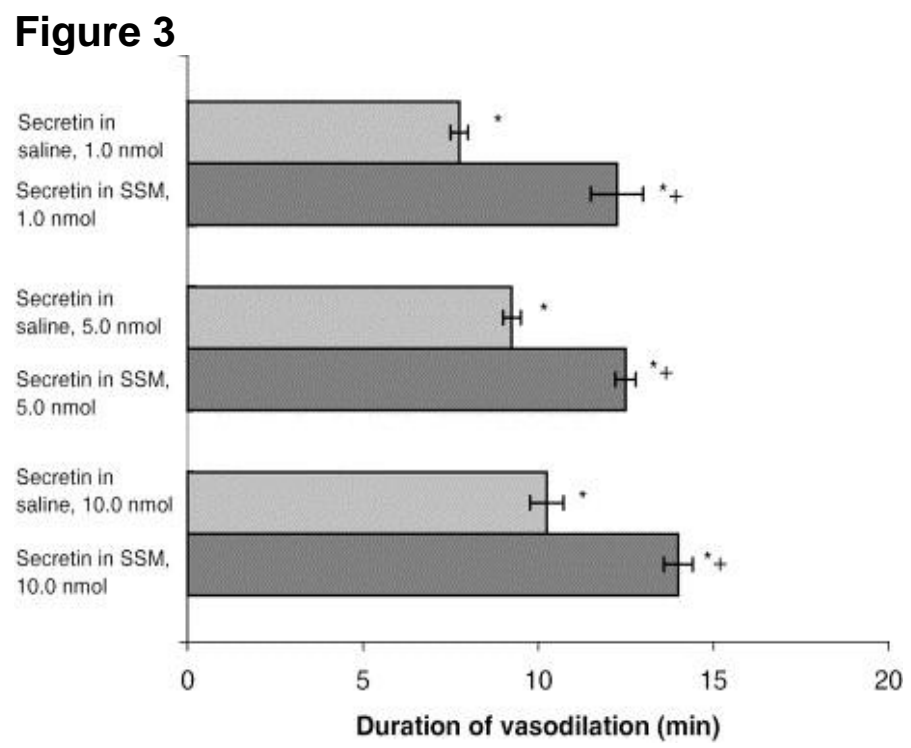

Liposomes have also been extensively studied for the delivery of peptides and proteins. Amphipathic or hydrophilic biological molecules could be encapsulated within 
the liposomal central aqueous cores [82, 83]. Hydrophobic amino acid residues within the primary sequence of protein/peptide, on the other hand, may insert into the lipid bilayers to interact with lipid acyl chains by hydrophobic interaction [25]. Alternatively, peptides and proteins could be added to preformed PEGylated liposomes to associate with the vesicles via the outer PEG region $[84,85]$. Similar to SSM associated VIP, liposomal VIP can be obtained by spontaneous interaction of VIP with PEGylated liposomes. Liposomal VIP exhibited increased $\alpha$ helicity, potentiation and prolongation of biological activity compared to VIP in buffer $[20,86]$. While free VIP is susceptible to plasma enzyme degradation and auto-hydrolysis (resulting in a short plasma half-life lasting over few minutes), liposomal VIP was observed to be stable for 8 days when incubated in human plasma at $37^{\circ} \mathrm{C}$ [74].

The first generation SLN is generally more suitable for incorporation of lipophilic peptides and proteins (e.g. cyclosporine A) due to hydrophobicity of their solid lipid matrices [21, 25, 87]. However, with appropriate choice of production method, substantial loading of relatively hydrophilic protein is still achievable with examples that include insulin, bovine serum albumin and lysozyme [88, 89]. Alternatively, hydrophilic biologic molecules can be chemically linked to lipid via salt formation or covalent linkage to form lipid drug conjugate (LDC; second generation SLN). The purified LDC bulk requires further processing, such as high pressure homogenization, to generate nanoparticles [90]. For SLN composed of PEG conjugated lipid, it is also highly possible that short amphiphilic peptides could interact with the outer PEG region of PEGylated SLN as what we have observed for SSM.

Depending on the hydrophilic/hydrophobic balance of the protein or peptide in concern, either $\mathrm{o} / \mathrm{w}$ or w/o nanoemulsion can be used as delivery system for these biologic molecules. The therapeutic agent is solubilized within the dispersed nanodroplets for protection against in vitro physical aggregation and in vivo enzymatic inactivation [91, 92].

\section{Safety improvement due to targeted delivery of drugs to sites of action by lipid nanocarriers}

A major cause of drug toxicity has been attributed to the non-specific biodistribution of drug molecules when administered into human body. One way in which nanosized carrier can help to dramatically reduce drug toxicity is by providing selective delivery to the intended site of action through targeting. Lipid nanocarriers can be targeted by two mechanisms; passive and active.

\section{Passive targeting}

Normal vasculature generally has a pore size below $4 \mathrm{~nm}$. In contrast, the "leaky vasculature" of solid tumor and inflamed tissues exhibit larger pore cutoff size that varies between 200 to $780 \mathrm{~nm}$ [23]. Therefore, while free drug molecules are typically small enough to permeate out of normal vasculature to be taken up by tissues all over the body, drugs encapsulated in nanocarriers are retained within the circulatory system due to bigger particle sizes. The lipid-based nanosized carriers are typically greater than $10 \mathrm{~nm}$ in diameter and cannot be cleared by the kidneys but exit capillaries at sites of leaky microvasculature. Altered biodistribution of the encapsulated drug increases drug 
accumulation at targeted tumor or inflamed sites and decreases drug concentration in normal healthy tissues, thereby potentiating drug efficacy while reducing systemic adverse reactions. This phenomenon is known as the enhanced permeability and retention (EPR) effect. Our laboratory has made use of this concept to bring about increased drug delivery to the inflamed joints of mice inflicted with collagen-induced arthritis (CIA) [32]. As a result of EPR, camptothecin loaded SSM showed superior antiinflammatory activity against collagen-induced arthritis in CIA mice compared to the free drug [32]. Similar application has been reported using SLN. When actarit, a poorly water soluble drug indicated for rheumatoid arthritis, formulated in SLN was administered to normal mice, in vivo drug biodistribution was altered to show decreased renal accumulation which was desirable due to the nephrotoxic side effect of actarit [35].

Incorporation of photosensitizer drugs in stealth liposomes have been shown to remarkably enhance the accumulation of the drugs in tumor tissues, thus avoiding the reported potential life-threatening thrombosis upon intravenous injection of some photosensitizer drugs [93]. In a different study, liposomes incorporating chlorin e6 (Ce6) trimethylester (for photodynamic therapy of cancer) was shown to lower the $\mathrm{LC}_{80}$ by approximately 53 folds in gastric cancer cells compared to $\mathrm{Ce} 6$ sodium salt and caused complete tumor remission in animal with gastric cancer [93]. m-PEG lipid micelles incorporating hydrophobic benzoporphyrin derivatives, tetraphenylporphin and pyropheophorbide derivatives have also been investigated for photodynamic therapy of cancer [94-96]. A recent review by Nadezda et al. gives a good overview of mechamisms of photoresponsive release of drugs from nanocarriers [97].

Since leaky vasculature is a common feature of solid tumors, many potent and highly toxic anticancer drugs have been formulated in lipid-based nanocarriers to take advantage of the EPR effect [22, 30,61, 64]. Doxorubicin is an example where the formulation plays an important role to improve drug safety and efficacy. In the commercial liposomal preparation of doxorubicin $\left(\right.$ Doxil $^{\circledR} /$ Caely $^{\circledR}$ ), the drug is encapsulated in PEGylated liposomes of approximately $90 \mathrm{~nm}$ in diameter. This liposomal formulation preferentially accumulates in tumors with decreased drug distribution to the myocardium secondary to passive targeting. Consequently, decreased incidence of cardiotoxicity has been reported with Doxil ${ }^{\circledR} /$ Caelyx ${ }^{\circledR}$ allowing higher cumulative drug dose in patients compared to the conventional doxorubicin solution (Adriamycin ${ }^{\circledR}$ ) [98]. For the same reason, severity of myelosuppression was also milder in patients taking Doxil ${ }^{\circledR} /$ Caelyx $^{\circledR}$ than Adriamycin ${ }^{\circledR}[8,98]$. Similar improvement was observed when doxorubicin was delivered in SSM [31]. A 5 fold increase in intra-tumor accumulation of doxorubicin was documented with subcutaneous injection of doxorubicin in SSM, compared to the free drug in mice bearing Lewis lung carcinoma tumor. Prolonged survival of mice and lower cardiac doxorubicin level were observed with the micellar formulation. Another non-PEGylated liposomal formulation of doxorubicin - Myocet ${ }^{\circledR}$ has been similarly reported to improve the therapeutic index of doxorubicin and reduce cardiotoxicity in patients with metastatic breast cancer [99].

Etoposide, a topoisomerase II inhibitor, is another water-insoluble chemotherapeutic agent commonly indicated for the treatment of lung cancer and testicular cancer [100]. As with many other anticancer drugs, it is associated with a multitude of side effects that can be potentially attenuated via delivery in lipid 
nanocarriers. When etoposide-loaded SLN were injected subcutaneously into mice bearing Dalton's lymphoma tumor xenograft, six folds higher drug concentration was detected in tumors compared to the free drug preparation. Conversely, significantly lower drug uptake by the reticuloendothelial system organs such as liver and spleen was recorded, indicating altered drug biodistribution due to EPR [36].

\section{Active targeting}

To further increase cellular uptake of drug moieties at the intended disease sites, surface modification of nanocarriers with specific ligands that bind to receptors overexpressed on target cells is an additional approach complementary to passive targeting. Common ligands employed for active targeting include peptides, small molecules and monoclonal antibodies $[23,101]$. These ligands generally aid to retain the nanomedicine at the disease site and in some cases enhance cellular internalization of the nanomedicine into the targeted cells via receptor-mediated endocytosis $[102,103]$.

Other than its therapeutic function, VIP has also been extensively utilized by our laboratory as a peptide ligand for active targeting [32, 59, 104, 105]. In breast cancer, the active targeting concept lies on the basis that VIP receptors are over-expressed in human breast cancer cells [104]. The ability of VIP ligand to augment cellular uptake of lipid micelles has been verified by quantum dots loaded, VIP-conjugated mixed micelles (QD-SSMM-VIP) [103]. Increased fluorescence signals (from the quantum dots) were detected in MCF-7 cells when incubated with QD-SSMM-VIP relative to micelles without VIP. Receptor specificity of VIP targeting was established by administration of excessive $\mathrm{PACAP}_{6-38}$, a PAC1 receptor antagonist, or galanin, an unrelated peptide with similar molecular mass as VIP, together with VIP to MCF-7 cells (Fig. 4) [103].

\section{Figure 4}
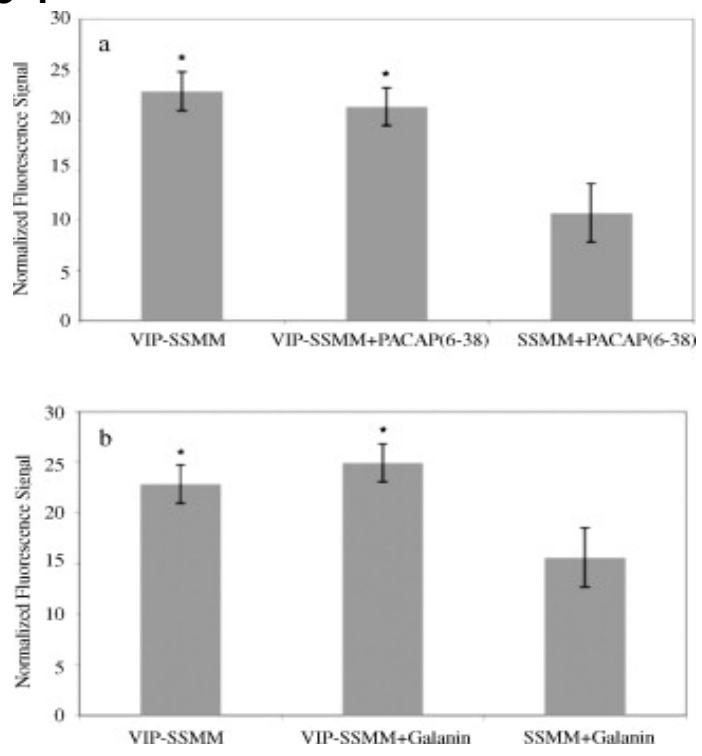

We have also developed ${ }^{99} \mathrm{Tc}-\mathrm{HMPAO}$ encapsulated sterically stabilized liposomes that were actively targeted with VIP for theragonostic purpsose [105]. Our study showed significant improvement in breast tumor uptake of ${ }^{99} \mathrm{Tc}-\mathrm{HMPAO}$ delivered in VIP conjugated liposomes compared to unconjugated carrier in a rodent breast tumor model 
induced in situ by $\mathrm{N}$-methyl nitrosourea (MNU) (Fig. 5). ${ }^{99} \mathrm{TC}-\mathrm{HMPAO}$ is a radiopharmaceutical used as diagnostic agent for breast tumor imaging. Increased tumor accumulation of ${ }^{99} \mathrm{Tc}$-HMPAO will therefore bring about increased detection sensitivity while reducing radioactivity exposure to the other healthy organs. Apart from this, Lovell et. al. have explored lipid nanocarriers for theragnosis, i.e. for visualization and treatment of tumor [106]. For this purpose lysophosphatidylcholine was conjgated with pyrorphophorbide to obtain lipid-prophyrin conjugates that self-assemble to form porphysomes. These 100nm sized structures were loaded with doxorubicin and demonstrated enhanced accumulation in tumor site and ablation of tumor following laser irradiation in animals. The formulation showed minimal toxicity even at high dose of $1000 \mathrm{mg} / \mathrm{kg}$ which highlights the safety of the formulation over inorganic photosensizers such as gold and silica nanoparticles which are known to have safety concerns [106]. A recent review by Allegra et. al. discusses various nanoparticles including lipid based carriers for theragnosis purposes [107].

In another study, enhanced cytotoxicity of paclitaxel encapsulated in SSMM and actively targeted through VIP (P-SSMM-VIP) was apparent in P-gp-mediated paclitaxel resistance $\mathrm{BC} 19 / 3$ cells $\left(\mathrm{IC}_{50}\right.$ of $59.76 \pm 11.27 \mathrm{ng} / \mathrm{ml}$ ), compared to P-SSMM and paclitaxel in DMSO ( $\left(\mathrm{IC}_{50}\right.$ of $136.7 \pm 23.0$ and $282.3 \pm 82.9 \mathrm{ng} / \mathrm{ml}$ respectively) [104]. Therefore, through VIP receptor targeting to amplify cellular drug uptake and potentially saturate the P-gp efflux pump, P-SSMM-VIP could possibly overcome paclitaxel resistance in multi-drug resistant breast cancer. In addition, based on the same notion, since VIP receptors are also expressed on immune cells (T cells and macrophages) that accumulate at sites of inflammation [108], active targeting using VIP was also applied to increase drug uptake into immune cells at the inflamed joints of CIA mice. Delivery of camptothecin using VIP conjugated SSM to CIA mice decreased the effective drug dose required for anti-arthritic effect to one-third of the dose needed when given in unconjugated micelles [32].

Other than VIP, a recent publication by Ashley et. al. reported the use of a novel targeting peptide, SP94 peptide, on a type of modified liposomal nanocarrier, named protocell, where the liposomal lipid bilayer encapsulate over a nanoporous silica core. Their study showed that the targeting moiety resulted in 10,000-fold higher binding affinity (as indicated by the respective $K_{d}$ values) for hepatocarcinoma cells compared to normal hepatocytes or endothelial cells in vitro [102].

\section{Figure 5}




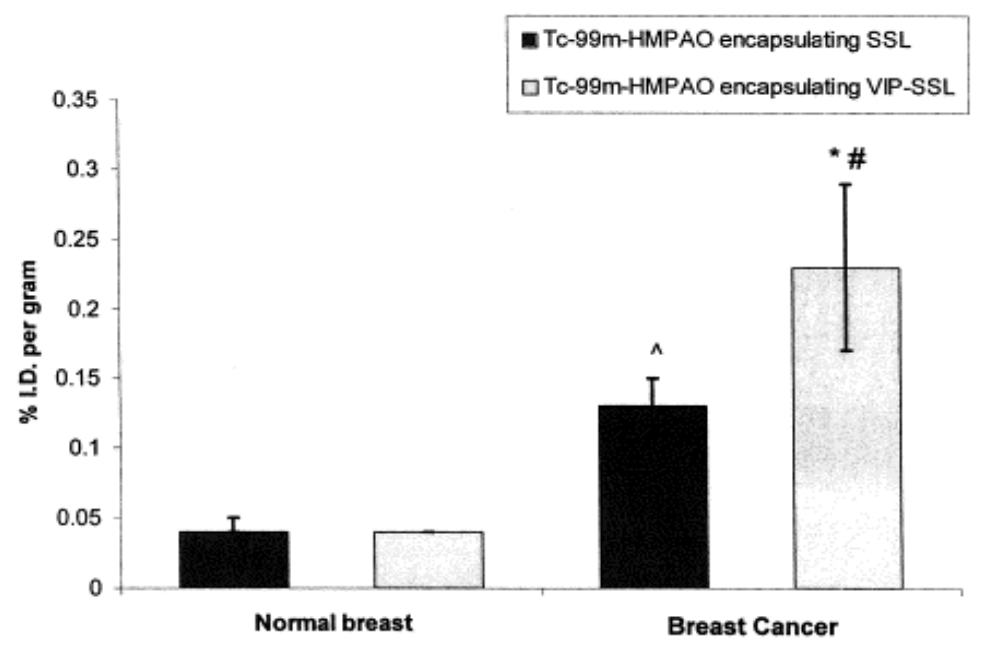

Monoclonal antibody ( $\mathrm{mAb}$ ) is another class of commonly used targeting moiety in drug delivery $[23,109,110]$. Either the whole antibody or the variable Fab fragment of the mAb can be chemically conjugated to the surface of lipid nanocarriers to bring about increased cellular uptake at the targeted disease sites. We have previously conjugated antihuman fibrinogen and intercellular adhesion molecule (ICAM-1) antibodies onto acoustically reflective liposomes composed of phospholipids and cholesterol [110]. When injected into miniswine with plaque formation induced in the carotid and iliofemoral arteries, antifibrinogen conjugated liposomes were found to attach to thrombi and atheroma while anti-ICAM-1 conjugated liposomes attached to early atheroma, providing ultrasonic image enhancement of the targeted structures compared to unconjugated liposomes. Incorporation of thrombolytic drugs into these antibody conjugated liposomes may be a potential future application to actively target drugs to the atherosclerotic plaques.

In another study, the monoclonal antibody $2 \mathrm{C} 5$ (mAb 2C5) has been covalently attached to the PEG region of phospholipid micelles and liposomes without interference of its specific binding ability to tumor cell surface bound nucleosome [61, 111]. When utilized as a targeting moiety for PEGylated liposomal doxorubicin, the immunoliposomes increased drug accumulation in colon and lewis lung carcinoma tumors and reduced drug distribution to the skin of mice compared to Doxil ${ }^{\circledR}$, leading to lower incidences of auricular erythema which is a dose-limiting cutaneous skin reaction seen with Doxil ${ }^{\circledR}$ treatment due to the drug vesicant property [111]. HER-2 receptor that is upregulated in breast and prostate cancer has also been actively targeted with antiHER2 mAb using paclitaxel loaded nanoemulsion to induce greater anti-tumor activity [112]. While mAb exhibits high receptor specificity which is important for targeting purpose, it is also critical to consider potential immunogenicity and toxicity of mAb. To date, hypersensitivity reactions as well as other potentially fatal side effects have been reported for different therapeutic mAbs currently under clinical investigation [113, 114]. Such safety concern must therefore be thoroughly addressed before mAb targeted nanocarriers can possibly progress into clinical trials. In a different study by the same group, PEGylated micelles or liposomes conjugated with TAT peptide or biotin with a $\mathrm{pH}$ sensitive hydrazone bond between PEG and PE was used to obtain $\mathrm{pH}$ sensitive nanocarriers [115]. At normal physiological $\mathrm{pH}$, the nanocarriers demonstrated minimal 
binding to avidin column or internalization into cells due to shielding of the biotin and TAT peptide by PEG chain. However at lower pH (5.0-6.0), the PEG layer detached due to acidic hydrolysis of hydrazone and the nanocarriers demonstrated strong retention onto avidin column and internalization into cells. Stimuli sensitive nanocarriers including lipid nanocarriers have been extensively discussed in reviews by Torchilin and Ganta et. al. [116, 117].

Among the small molecule targeting agents, folate is often used in the delivery of anticancer drugs as these receptors are found to be over-expressed in many different malignant human tumors. As such, folate coated SLN has been utilized to improve therapeutic efficacy of neutron capture therapy by increasing tumor (human nasopharyngeal carcinoma) uptake and retention of gadolinium (loaded in SLN) compared to uncoated SLN [118]. Similar biodistribution improvement has also been reported for folate conjugated liposomes loaded with doxorubicin or 5-fluorouracil compared to their unconjugated counterparts [119, 120]. However, off target effects should not be overlooked when using folate receptors for targeting purpose.

Besides covalently conjugating ligands onto nanoparticle surfaces, cholesterolrich nanoemulsion exhibits another unique mechanism of acquiring targeting property after administration into blood stream. When circulating in plasma, the cholesterol-rich nanoparticulate systems undergo interaction with apolipoprotein $E$ molecules. The resulting complexes are recognizable by low density lipoprotein (LDL) receptors and hence taken up by cells expressing LDL receptors. Since LDL receptors are overexpressed in several cancer cell types, cholesterol-rich nanoemulsion has been utilized to increase drug distribution to specific tumor cells [121]. Alternatively, core or surface loading of LDL into lipid-based nano-delivery systems will also allow active targeting of these nanocarriers to tumor cells over-expressing LDL receptors [122].

When preparing an actively targeted nanomedicine, the choice of targeting ligand should be chosen with great care. Over expression of the ligand receptor at the diseased tissue is important but not sufficient. If the target receptor is also expressed at the normal tissues then off target effect can cause serious toxic effects since a single nanoparticle can deliver relatively high drug dose to healthy tissues. VIP receptors are ideal targets with this respect. They are only expressed at extravascular space and overexpressed at cancer and inflamed tissues. Since VIP conjugated nanocarrier can only extravasate out at leaky vasculatures of disease sites, no adverse effects of the peptide (such as vasodilatory effect) can be observed on healthy tissues. This was experimentally demonstrated when parenteral administration of the free peptide (in buffer) to animals resulted in drastic hypotension which was significantly ameliorated when VIP was delivered in SSM demonstrating that non-specific extravasation is eliminated (Fig. 6) [43].

\section{Figure 6}




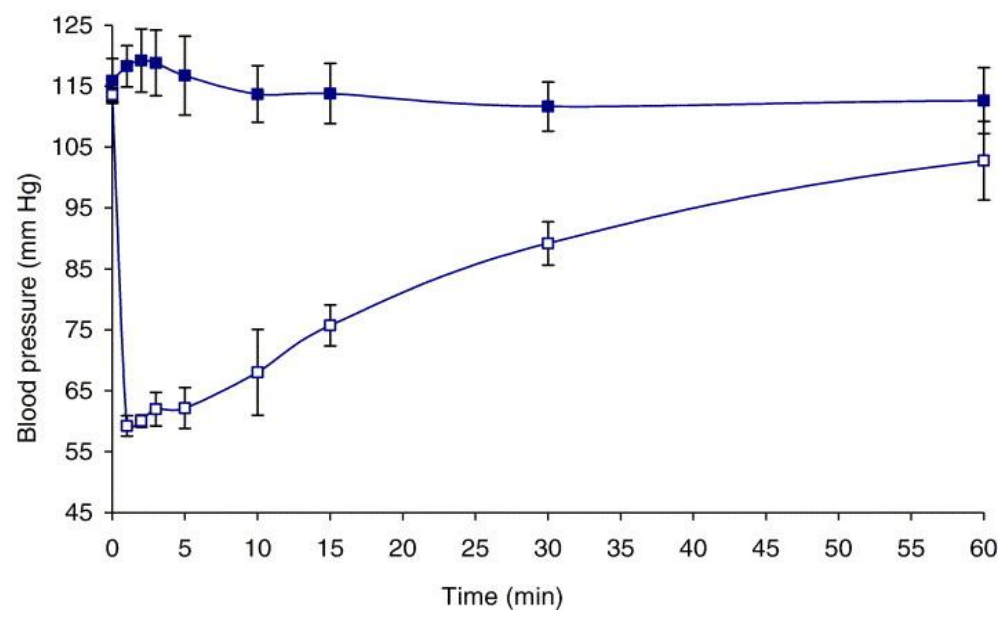

\section{Safety improvement by altering pharmacokinetic profiles of drugs using lipid nanocarriers}

Encapsulation or association of drugs to lipid nanocarriers typically alters the intrinsic pharmacokinetic profiles of the drug molecules. Delivery systems can act as intravascular drug depots and exhibit prolonged drug release, with controlled release (drug release in response to stimuli or time) profile depending principally on the lipid degradation rate and/or drug diffusion rate through the lipid constructs [20, 21, 25, 33]. Factors such as drug loading, drug concentration and drug aggregation within the lipid core of the nanocarriers affect drug release kinetics. Delivery of drugs in these lipid nanocarriers generally resulted in a more sustained release (slow release of drug over a period of time) profile that can minimize drug toxicity, dosing frequency and plasma drug concentration fluctuation. Ideally, for targeted systems it is desired to have no drug release during circulation so that most drug dose is accumulated in the target tissue. Both sustained or no drug release systems will in turn improve therapeutic safety and efficacy.

Particularly for SLN, the solid state of the lipid matrices at body temperature results in much slower degradation, making them attractive carriers for formulation of long-acting controlled release preparations over extended period [21, 25]. Furthermore, depending on the drug deposition pattern in the solid lipid matrices (drug-enriched core, solid solution or drug-enriched shell), drug release characteristics can be varied to our advantage for attainment of the desired release profile. For instance, a biphasic drug release has been observed for the drug-enriched shell model via an initial burst release from the outer shell followed by a more gradual drug release from the lipid core. The drug-enriched core model, on the other hand, can be employed to achieve a more prolonged sustained drug release effect due to increased drug diffusional distance from the lipid matrix core [90]. Guo et. al. have utilized SLN incorporating 2-methoxyestradiol and loaded it onto hydrogels to achieve thermosenstive release of the drug upon systemic administration [123]. A prolonged release profile over 46 days was observed in the release media and the SLN loaded hydrogels demonstrated reversible thermosensitive property indicating that the formulation could be used to provide enhanced accumulation and prolonged delivery of drug to tumor sites to improve efficacy of cancer treatment. 
As for nanosuspension, those nanoparticulate drugs that dissolve rapidly (in the order of seconds or minutes) in systemic circulation will show similar pharmacokinetic profiles as drug solutions. Conversely, slow dissolving particles that persist as nanoparticulate systems stabilized by surfactant coating in vivo behave similarly to liposomes or SLN with respect to their pharmacokinetic characteristics [22, 58, 72]. The organ distribution of a clofazamine (an anti-microbial drug) nanosuspension, injected intravenously, was not significantly different from that of a comparative liposomal preparation [41].

For targeted systems ideally no drug release during intravascular transport is preferred, so that high drug concentration is achieved at the target tissue. For example the breaking of drug loaded phospholipid micellar system can be avoided by incorporating required amount of empty micelles in the formulation to retain the intermolecular concentration upon dilution. Both for non-targeted and targeted systems the nanocarriers need to circulate long time in the blood and should not be cleared by opsonization. The most effective way to decrease opsonization is to attach hydrophilic polymers such as PEG to the particle surface.

\section{PEGylation of lipid-based nanocarriers}

PEGylation is an important surface modification widely applied to nanoparticulate systems to reduce immunogenicity and impart long circulating property. Nanoparticles possess tremendously high surface area that can potentially interact with immune cells and plasma proteins when circulating in blood stream [124]. Certain bound protein increases recognition of the nanoparticles by the reticuloendothelial system (RES), such as IgG, complement factors and fibrinogen. Such interaction may therefore promote phagocytosis and rapid removal of the nanoparticles from systemic circulation. Although the mechanism of nanoparticle-protein interaction is still not completely understood, hydrophobicity of nanoparticle surface has been shown to increase the amount and influence the type of protein bound to nanoparticles. Hypdrophobic particles are generally more rapidly opsonized compared to hydrophilic particles. Other than hydrophobic interaction, electrostatic interaction (due to nanoparticle surface charge) is another potential means of nanoparticle-protein association [125]. Lundqvist et. al. reported that hydrophobic polystyrene nanoparticles bound extensively to immunoglobulins and proteins when incubated in plasma. Conversely, these interactions were significantly reduced when the nanoparticle surface was modified with hydrophilic polyethylene glycol (PEG) [126, 127]. For lipid-based nanocarriers, PEGylation is useful in shielding the hydrophobic nanoparticle surface and any surface charge that is presented. PEGylation typically involves chemical attachment of PEG chains onto individual lipid monomers which are subsequently incorporated into the carrier systems [128]. The resulting PEGylated lipid-based nano-system has a hydrophobic lipid structure camouflaged by an outer PEG region. However, the coverage of PEG layer on particle surface is very critical. Unfortunately for liposomal preparations only limited amount of PEGylated lipid can be incorporated. A recent study has shown uptake of PEGylated nanoparticles by macrophages, and size of the particles affects this uptake more than surface charge [129].

In aqueous environment, the PEG chains are strongly hydrated, resulting in an

"exclusion volume" which prevents approach of other molecules [130]. Through this 
mechanism, there is reduced recognition of the carrier systems by the opsonins and hence RES and their consequent sequestration [131]. The avoidance of RES renders the formulation long circulating as demonstrated by Lee et. al. whereby decreased clearance of drug from the general circulation was observed when given in PEGylated liposomes relative to non-PEGylated control intravenously [132]. Similar observation was observed with nanoemulsion stabilized with DSPE-PEG in contrast to its nonPEGylated counterpart [133]. PEGylation thereby works co-operatively with the nanocarriers, which retard drug release via a diffusional barrier effect, to bring about prolonged and sustained drug pharmacological actions [21, 22, 101]. Other than reducing peak-to-trough plasma drug fluctuation as mentioned earlier, prolonged acting formulations also decrease the dosing frequency needed which may likely improve patient compliance and reduce risk of medication error [134]. Furthermore, sustained plasma drug concentration is at times crucial for certain drug therapies, such as antivirus treatment, to ensure therapeutic efficacy [135]. In addition, the long circulating feature of PEGylated nanocarriers is an important requirement for effective passive and active targeting. With longer retention time within the systemic circulation, there is increased opportunity for the drug-carrier constructs to extravasate at locations of leaky vasculature and be taken up into cells via receptor-mediated endocytosis [136].

When formulating PEGylated lipid-based nanocarriers, the molecular weight of PEG chain is a critical consideration as it affects aqueous solubility of the PEGylated phospholipid molecule, size of the resulting carrier and its solubilizing capability for hydrophobic drugs [22, 24, 137]. Phospholipids PEGylated with longer PEG chains have increased solubility in aqueous media, giving rise to higher CMCs and hence fewer micelles at the same lipid concentrations (above CMCs). Therefore, SSM composed of DSPE-PEG 5000 exhibited lower solubilizing capacity for poorly water soluble drugs (e.g. diazepam) compared to DSPE-PEG 2000 [24]. Another possible reason is the greater hydrophobic to hydrophilic phase ratio of SSM with shorter PEG, resulting in more efficient loading of water-insoluble drugs compared to micelles with longer PEG chains. Moreover, as a linker between lipid molecule and its targeting ligand, the length of the PEG spacer will also influence efficiency of active targeting [138]. The PEG linker should ideally be sufficiently long to project outwards and allow "nonhindered" interaction of the conjugated ligand to its targeted receptor. It should be highlighted that PEG is definitely not the only polymer that can be used to alter surface property of lipid-based nanoparticles. Other polymers and polysaccharides have also been utilized for similar applications, e.g. poloxamer, though not as commonly seen as PEG [125].

\section{Lipid nanocarriers reduce drug interaction with plasma components}

The interaction of drug molecules especially hydrophobic drugs to plasma protein is a known crucial factor affecting in vivo pharmacokinetic and biodistribution profiles of drug. As described earlier for nanoparticles, binding of drug molecules to opsonins would similarly increase immunogenicity and induce rapid clearance from systemic circulation [125]. Drug molecules that bind extensively to plasma protein usually exhibit non-linear saturable pharmacokinetics [139]. Under specific circumstances, such as saturation of plasma protein-drug binding sites with rapid intravenous drug administration or disease conditions producing hypoalbuminaemia, plasma protein 
displacement reactions can become clinically important to result in drastic increase in circulatory free drug concentrations, leading to dose-related drug toxicity [140, 141]. Therefore, dose titration and therapeutic drug concentration monitoring is often required for this category of drugs to prevent toxicity in clinical setting.

In contrast, when drugs are encapsulated within lipid-based nanocarriers, there will be reduced chance of direct physical contact and interaction between the encapsulated drug moieties and circulating blood components. Moreover, lipid composition of nanocarriers can be tailored to further minimize plasma protein interaction. The addition of cholesterol to the neutral phospholipid, 1,2- distearoyl-snglycero-3-phosphocholine (DSPC) liposomes has been shown to reduce protein adsorption, possibly due to decreased membrane surface defects that served as potential sites for protein binding [52]. PEGylation of lipid-based nanocarriers is another strategy as described above $[52,130,142]$. For drug molecules that exert direct toxicity on erythrocytes and/or leukocytes, the nanocarriers will further act as barriers to prevent the encapsulated drugs from exerting unwanted cellular toxicities on circulating blood cells before the drug molecules reach their target sites of action [143, 144]. Amphotericin $B$ is an anti-fungal drug with undesirable hematological side effects. Delivery of amphotericin $B$ in liposomes $\left(\right.$ Ambisome ${ }^{\circledR}$ ), lipid micelles and nanosuspension reduced hemolysis of erythrocytes without compromising its anti-fungal activity [29, 145]. Similarly, encapsulation of all-trans retinoic acid (ATRA) within SLN showed diminished hemolytic potential compared to free ATRA when incubated with red blood cells in vitro [66].

\section{Conclusions}

Lipid-based nanocarriers have been receiving increasing attention in the field of pharmaceutical research due to growing importance of nanotechnology as well as the established safety of their lipid components. Besides providing safe vehicles to increase solubility and stability of hydrophobic drugs and biologics, these nanocarriers could also help to drastically reduce drug-related toxicities through reduction of non-specific biodistribution by passive and active targeting, preventing drug sequestration by RES via surface modification of nanocarriers and minimizing drug interaction with other components of the circulatory system by acting as a physical barrier. In view of the heightening attention on drug safety, lipid-based nanocarrier is therefore a promising option for formulating drug products. Selection of the optimal lipid-based nanocarrier for delivery of specific drug entity depends on many factors including drug solubility profiles, thermosensitivity and crystalline property. Heat-labile drugs, for instance, will not be appropriate candidates for formulating into nanosuspension due to the high energy level input during production which will generate intense heat and elevate temperature [22, 25]. When formulating nanoemulsions, SLN and nanosuspensions, the choice of the appropriate surface active agent is also very important as they contribute significantly to the overall safety of the pharmaceutical products.

From the industrial perspective, ease of mass production with maintenance of product consistency and quality control are crucial considerations. Compared to liposomes, SLN and nanosuspensions, thermodynamically stable nanoemulsions and lipid micelles, which develop spontaneously in aqueous media with well-defined reproducible particle size, are relatively easier to manufacture on a large scale $[23,26]$. 
For nanosuspensions, variation in particle size due to potential agglomeration, varying crystal size and shape can increase product variability. Insufficient mixing is another factor that can affect dosing reproducibility [58]. In addition, sterilization of lipid nanoformulations is often another issue of concern for manufacturers. Heat sterilization is generally inappropriate for most lipid-based delivery systems since many lipid constituents degrade at high temperature. Certain delivery systems are also unstable at high temperature, such as nanoemulsions and nanosuspensions, due to susceptibility to phase inversion, flocculation and coalescence in extreme heat. Therefore, aseptic technique and sterile filtration are the common viable options adopted [26, 58]. However, these procedures may increase difficulty of manufacturing process and the corresponding production cost. Furthermore, to address another essential consideration for product commercialization: shelf stability, lyophilization studies of the different lipidbased nanocarrier systems need to be extensively developed.

In view of these concerns, lipid nanomicelles such as SSM stand very promising compared to other lipid nanocarriers. They can effectively solubilize hydrophobic drugs and associate with amphiphilic peptides and deliver them to their target sites due to their ideal size $(\sim 15 \mathrm{~nm})$. They are easy to prepare, can be sterilized by filtration, lyophilized without any cryo or lyoprotectant and scaled-up, therefore have great promise to be utilized in future nanomedicines. However it is important to note that molecular weight, polarity and structure of molecules influence loading of drugs onto lipid micelles and therefore these nanostructures cannot be utilized to deliver all types of hydrophobic drugs and amphiphilic peptides.

\section{REFERENCES}

[1] I. Ojima,Medicinal chemistry at a crossroads: Challenges and new possibilities, Future Med.Chem. 1 (2009) 401-403.

[2] J. Splawinski, J. Kuzniar, K. Filipiak, W. Zielinski, Evaluation of drug toxicity in clinical trials, Sci.Eng.Ethics 12 (2006) 139-145.

[3] S. Okie,Safety in numbers--monitoring risk in approved drugs, N.Engl.J.Med. 352 (2005) 1173-1176.

[4] J. M. Brophy,Cardiovascular effects of cyclooxygenase-2 inhibitors, Curr.Opin.Gastroenterol. 23 (2007) 617-624.

[5] S. Bunniran, D. J. McCaffrey III, J. P. Bentley, A. S. Bouldin, Pharmaceutical product withdrawal: Attributions of blame and its impact on trust, Res.Social Admin.Pharm. 5 (2009) 262-273.

[6] T. J. Moore, M. R. Cohen, C. D. Furberg, Serious adverse drug events reported to the food and drug administration, 1998-2005, Arch.Intern.Med. 167 (2007) 1752-1759.

[7] L. H. Reddy,Drug delivery to tumours: Recent strategies, J.Pharm.Pharmacol. 57 (2005) 1231-1242.

[8] R. Soloman, A. A. Gabizon, Clinical pharmacology of liposomal anthracyclines: Focus on pegylated liposomal doxorubicin, Clin.Lymphoma Myeloma 8 (2008) 21-32.

[9] G. Vassal, C. Pondarré, I. Boland, C. Cappelli, A. Santos, C. Thomas, E. Lucchi, K. Imadalou, F. Pein, J. Morizet, A. Gouyette, Preclinical development of camptothecin derivatives and clinical trials in pediatric oncology, Biochimie 80 (1998) 271-280. 
[10] M. Marangolo, C. Bengala, P. F. Conte, M. Danova, P. Pronzato, G. Rosti, P. Sagrada, Dose and outcome: The hurdle of neutropenia (review), Oncol.Rep. 16 (2006) 233-248.

[11] N. Lamanna, M. A. Weiss, Purine analogue-based chemotherapy regimens for second-line therapy in patients with chronic lymphocytic leukemia, Semin.Hematol. 43, Supplement 2 (2006) S44-S49.

[12] G. Metro, A. Fabi, M. Russillo, P. Papaldo, M. De Laurentiis, G. Ferretti, D. Pellegrini, C. Nuzzo, V. Graziano, P. Vici, M. Introna, A. Felici, F. Cognetti, P. Carlini, Taxanes and gemcitabine doublets in the management of HER-2 negative metastatic breast cancer: Towards optimization of association and schedule, Anticancer Res. 28 (2008) 1245-1258.

[13] S. M. Swain, J. C. Arezzo, Neuropathy associated with microtubule inhibitors: Diagnosis, incidence, and management, Clin.Adv.Hematol.Oncol. 6 (2008) 455-467.

[14] A. J. ten Tije, J. Verweij, W. J. Loos, A. Sparreboom, Pharmacological effects of formulation vehicles : Implications for cancer chemotherapy, Clin.Pharmacokinet. 42 (2003) 665-685.

[15] M. J. Hawkins, P. Soon-Shiong, N. Desai, Protein nanoparticles as drug carriers in clinical medicine, Adv.Drug Deliv.Rev. 60 (2008) 876-885.

[16] F. Locatelli, L. Del Vecchio, P. Pozzoni, Pure red-cell aplasia "epidemic"--mystery completely revealed? Perit.Dial.Int. 27 Suppl 2 (2007) S303-7.

[17] $\mathrm{H}$. Schellekens, Factors influencing the immunogenicity of therapeutic proteins, Nephrol.Dial.Transplant. 20 Suppl 6 (2005) vi3-9.

[18] P. Simamora, S. Pinsuwan, J. M. Alvarez, P. B. Myrdal, S. H. Yalkowsky, Effect of pH on injection phlebitis, J.Pharm.Sci. 84 (1995) 520-522.

[19] J. L. Johnson, S. H. Yalkowsky, Reformulation of a new vancomycin analog: An example of the importance of buffer species and strength, AAPS PharmSciTech 7 (2006) E5.

[20] H. Onyuksel, F. Sejourne, H. Suzuki, I. Rubinstein, Human VIP-alpha: A longacting, biocompatible and biodegradable peptide nanomedicine for essential hypertension, Peptides 27 (2006) 2271-2275.

[21] M. Rawat, D. Singh, S. Saraf, S. Saraf, Lipid carriers: A versatile delivery vehicle for proteins and peptides, Yakugaku Zasshi 128 (2008) 269-280.

[22] P. P. Constantinides, M. V. Chaubal, R. Shorr, Advances in lipid nanodispersions for parenteral drug delivery and targeting, Adv.Drug Deliv.Rev. 60 (2008) 757-767.

[23] V. P. Torchilin,Micellar nanocarriers: Pharmaceutical perspectives, Pharm.Res. 24 (2007) 1-16.

[24] B. Ashok, L. Arleth, R. P. Hjelm, I. Rubinstein, H. Onyuksel, In vitro characterization of PEGylated phospholipid micelles for improved drug solubilization: Effects of PEG chain length and PC incorporation, J.Pharm.Sci. 93 (2004) 2476-2487.

[25] S. Martins, B. Sarmento, D. C. Ferreira, E. B. Souto, Lipid-based colloidal carriers for peptide and protein delivery-liposomes versus lipid nanoparticles, Int.J.Nanomedicine 2 (2007) 595-607.

[26] D. K. Sarker,Engineering of nanoemulsions for drug delivery, Curr.Drug Deliv. 2 (2005) 297-310. 
[27] A. Krishnadas, I. Rubinstein, H. Onyuksel, Sterically stabilized phospholipid mixed micelles: In vitro evaluation as a novel carrier for water-insoluble drugs, Pharm. Res. 20 (2003) 297-302.

[28] A. Samad, Y. Sultana, M. Aqil, Liposomal drug delivery systems: An update review, Curr.Drug Deliv. 4 (2007) 297-305.

[29] S. P. Vyas, S. Gupta, Optimizing efficacy of amphotericin B through nanomodification, Int.J.Nanomedicine 1 (2006) 417-432.

[30] K. L. Hennenfent, R. Govindan, Novel formulations of taxanes: A review. old wine in a new bottle? Ann. Oncol. 17 (2006) 735-749.

[31] N. Tang, G. Du, N. Wang, C. Liu, H. Hang, W. Liang, Improving penetration in tumors with nanoassemblies of phospholipids and doxorubicin, J.Natl.Cancer Inst. 99 (2007) 1004-1015.

[32] O. M. Koo, I. Rubinstein, H. Onyuksel, Actively targeted low-dose camptothecin as a safe, long-acting, disease-modifying nanomedicine for rheumatoid arthritis, Pharm.Res. 28 (2011) 776-787.

[33] H. Onyuksel, H. Ikezaki, M. Patel, X. P. Gao, I. Rubinstein, A novel formulation of VIP in sterically stabilized micelles amplifies vasodilation in vivo, Pharm.Res. 16 (1999) 155-160.

[34] M. N. Sahib, Y. Darwis, K. K. Peh, S. A. Abdulameer, Y. T. Tan, Rehydrated sterically stabilized phospholipid nanomicelles of budesonide for nebulization: Physicochemical characterization and in vitro, in vivo evaluations, Int.J.Nanomedicine 6 (2011) 2351-2366.

[35] J. Ye, Q. Wang, X. Zhou, N. Zhang, Injectable actarit-loaded solid lipid nanoparticles as passive targeting therapeutic agents for rheumatoid arthritis, Int.J.Pharm. 352 (2008) 273-279.

[36] L. Harivardhan Reddy, R. K. Sharma, K. Chuttani, A. K. Mishra, R. S. R. Murthy, Influence of administration route on tumor uptake and biodistribution of etoposide loaded solid lipid nanoparticles in dalton's lymphoma tumor bearing mice, J.Controlled Release 105 (2005) 185-198.

[37] M. O. Oyewumi, R. A. Yokel, M. Jay, T. Coakley, R. J. Mumper, Comparison of cell uptake, biodistribution and tumor retention of folate-coated and PEG-coated gadolinium nanoparticles in tumor-bearing mice, J.Controlled Release 95 (2004) 613-626.

[38] Y. Waknine, FDA approvals: Nascobal nasal spray, PTC 124, tocosol paclitaxel, Medscape medical news (2005).

[39] K. K. Singh, S. K. Vingkar, Formulation, antimalarial activity and biodistribution of oral lipid nanoemulsion of primaquine, Int.J.Pharm. 347 (2008) 136-143.

[40] E. Olavarria, M. Hassan, A. Eades, C. Nilsson, A. Timms, J. Matthews, C. Craddock, E. Kanfer, J. Apperley, J. Goldman, A phase I/II study of multiple-dose intravenous busulfan as myeloablation prior to stem cell transplantation, Leukemia 14 (2000) 1954-1959.

[41] K. Peters, S. Leitzke, J. E. Diederichs, K. Borner, H. Hahn, R. H. Muller, S. Ehlers, Preparation of a clofazimine nanosuspension for intravenous use and evaluation of its therapeutic efficacy in murine mycobacterium avium infection, J.Antimicrob.Chemother. $45(2000) 77-83$. 
[42] M. J. Copland, T. Rades, N. M. Davies, M. A. Baird, Lipid based particulate formulations for the delivery of antigen, Immunol.Cell Biol. 83 (2005) 97-105.

[43] O. M. Koo, I. Rubinstein, H. Onyuksel, Role of nanotechnology in targeted drug delivery and imaging: A concise review, Nanomed.Nanotechnol.Biol.Med. 1 (2005) 193212.

[44] K. Jain, P. Kesharwani, U. Gupta, N. K. Jain, Dendrimer toxicity: Let's meet the challenge, Int.J.Pharm. 394 (2010) 122-142.

[45] K. Kostarelos, The long and short of carbon nanotube toxicity, Nat.Biotechnol. 26 (2008) 774-776.

[46] C. M. Goodman, C. D. McCusker, T. Yilmaz, V. M. Rotello, Toxicity of gold nanoparticles functionalized with cationic and anionic side chains, Bioconjug.Chem. 15 (2004) 897-900.

[47] S. J. Soenen, M. De Cuyper, Assessing iron oxide nanoparticle toxicity in vitro: Current status and future prospects, Nanomedicine (Lond) 5 (2010) 1261-1275.

[48] Y. L. Hu, W. Qi, F. Han, J. Z. Shao, J. Q. Gao, Toxicity evaluation of biodegradable chitosan nanoparticles using a zebrafish embryo model, Int.J.Nanomedicine 6 (2011) 3351-3359.

[49] G. Cevc, Phospholipids handbook, Marcel Dekker Inc, New York, USA, 1993.

[50] C. Martin A,Lipid clearance and total parenteral nutrition: The importance of monitoring plasma lipids, Nutrition 16 (2000) 774-775.

[51] M. C. Pedroso de Lima, S. Neves, A. Filipe, N. Duzgunes, S. Simoes, Cationic liposomes for gene delivery: From biophysics to biological applications, Curr.Med.Chem. 10 (2003) 1221-1231.

[52] S. C. Semple, A. Chonn, P. R. Cullis, Interactions of liposomes and lipid-based carrier systems with blood proteins: Relation to clearance behaviour in vivo, Adv.Drug Deliv.Rev. 32 (1998) 3-17.

[53] S. M. Moghimi, A. J. Andersen, S. H. Hashemi, B. Lettiero, D. Ahmadvand, A. C. Hunter, T. L. Andresen, I. Hamad, J. Szebeni, Complement activation cascade triggered by PEG-PL engineered nanomedicines and carbon nanotubes: The challenges ahead, J.Control.Release 146 (2010) 175-181.

[54] I. Hamad, A. C. Hunter, J. Szebeni, S. M. Moghimi, Poly(ethylene glycol)s generate complement activation products in human serum through increased alternative pathway turnover and a MASP-2-dependent process, Mol.Immunol. 46 (2008) 225-232.

[55] M. R. Sherman, L. D. Williams, M. A. Sobczyk, S. J. Michaels, M. G. Saifer, Role of the methoxy group in immune responses to mPEG-protein conjugates, Bioconjug.Chem. 23 (2012) 485-499.

[56] M. Ohnish, H. Sagitani, The effect of nonionic surfactant structure on hemolysis, J. Am. Oil. Chem. Soc. 70 (1993) 297-305.

[57] M. A. Partearroyo, H. Ostolaza, F. M. Goñi, E. Barberá-Guillem, Surfactant-induced cell toxicity and cell lysis: A study using B16 melanoma cells, Biochem.Pharmacol. 40 (1990) 1323-1328.

[58] J. Wong, A. Brugger, A. Khare, M. Chaubal, P. Papadopoulos, B. Rabinow, J. Kipp, J. Ning, Suspensions for intravenous (IV) injection: A review of development, preclinical and clinical aspects, Adv.Drug Deliv.Rev. 60 (2008) 939-954. 
[59] H. Onyuksel, P. S. Mohanty, I. Rubinstein, VIP-grafted sterically stabilized phospholipid nanomicellar 17-allylamino-17-demethoxy geldanamycin: A novel targeted nanomedicine for breast cancer, Int.J.Pharm. 365 (2009) 157-161.

[60] H. Cesur, I. Rubinstein, A. Pai, H. Onyuksel, Self-associated indisulam in phospholipid-based nanomicelles: A potential nanomedicine for cancer, Nanomedicine 5 (2009) 178-183.

[61] R. R. Sawant, R. M. Sawant, V. P. Torchilin, Mixed PEG-PE/vitamin E tumortargeted immunomicelles as carriers for poorly soluble anti-cancer drugs: Improved drug solubilization and enhanced in vitro cytotoxicity, Eur.J.Pharmaceutics Biopharmaceutics 70 (2008) 51-57.

[62] G. A. Peyman, B. Khoobehi, M. Tawakol, J. A. Schulman, H. A. Mortada, H. Alkan, R. Fiscella, Intravitreal injection of liposome-encapsulated ganciclovir in a rabbit model, Retina 7 (1987) 227-229.

[63] E. Ojewole, I. Mackraj, P. Naidoo, T. Govender, Exploring the use of novel drug delivery systems for antiretroviral drugs, Eur.J.Pharmaceutics Biopharmaceutics 70 (2008) 697-710.

[64] X. Yang, X. Zhao, M. A. Phelps, L. Piao, D. M. Rozewski, Q. Liu, L. J. Lee, G. Marcucci, M. R. Grever, J. C. Byrd, J. T. Dalton, R. J. Lee, A novel liposomal formulation of flavopiridol, Int.J.Pharm. 365 (2009) 170-174.

[65] S. C. Yang, L. F. Lu, Y. Cai, J. B. Zhu, B. W. Liang, C. Z. Yang, Body distribution in mice of intravenously injected camptothecin solid lipid nanoparticles and targeting effect on brain, J.Controlled Release 59 (1999) 299-307.

[66] S. Lim, M. Lee, C. Kim, Altered chemical and biological activities of all-trans retinoic acid incorporated in solid lipid nanoparticle powders, J.Controlled Release 100 (2004) 53-61.

[67] Y. Gupta, A. Jain, S. K. Jain, Transferrin-conjugated solid lipid nanoparticles for enhanced delivery of quinine dihydrochloride to the brain, J.Pharm.Pharmacol. 59 (2007) 935-940.

[68] K. Manjunath, V. Venkateswarlu, Pharmacokinetics, tissue distribution and bioavailability of clozapine solid lipid nanoparticles after intravenous and intraduodenal administration, J.Controlled Release 107 (2005) 215-228.

[69] F. Podlogar, M. Gašperlin, M. Tomšič, A. Jamnik, M. B. Rogač, Structural characterisation of water-Tween $40 \AA /$ Imwitor $308 \AA$-isopropyl myristate microemulsions using different experimental methods, Int.J.Pharm. 276 (2004) 115-128.

[70] J. B. Tagne, S. Kakumanu, R. J. Nicolosi, Nanoemulsion preparations of the anticancer drug dacarbazine significantly increase its efficacy in a xenograft mouse melanoma model, Mol.Pharm. 5 (2008) 1055-1063.

[71] J. B. Tagne, S. Kakumanu, D. Ortiz, T. Shea, R. J. Nicolosi, A nanoemulsion formulation of tamoxifen increases its efficacy in a breast cancer cell line, Mol.Pharm. 5 (2008) 280-286.

[72] B. E. Rabinow, Nanosuspensions in drug delivery, Nat.Rev.Drug Discov. 3 (2004) 785-796. 
[73] M. Zander, S. Madsbad, J. L. Madsen, J. J. Holst, Effect of 6-week course of glucagon-like peptide 1 on glycaemic control, insulin sensitivity, and $\beta$-cell function in type 2 diabetes: A parallel-group study, The Lancet 359 (2002) 824-830.

[74] A. Krishnadas, H. Onyuksel, I. Rubinstein, Interactions of VIP, secretin and PACAP(1-38) with phospholipids: A biological paradox revisited, Curr.Pharm.Des. 9 (2003) 1005-1012.

[75] S. Gandhi, T. Tsueshita, H. Onyuksel, R. Chandiwala, I. Rubinstein, Interactions of human secretin with sterically stabilized phospholipid micelles amplify peptide-induced vasodilation in vivo, Peptides 23 (2002) 1433-1439.

[76] S. B. Lim, I. Rubinstein, H. Onyuksel, Freeze drying of peptide drugs selfassociated with long-circulating, biocompatible and biodegradable sterically stabilized phospholipid nanomicelles, Int.J.Pharm. 356 (2008) 345-350.

[77] B. Ashok, I. Rubinstein, T. Tsueshita, H. Onyuksel, Effects of peptide molecular mass and PEG chain length on the vasoreactivity of VIP and PACAP1-38 in pegylated phospholipid micelles, Peptides 25 (2004) 1253-1258.

[78] S. Dagar, H. Onyuksel, S. Akhter, A. Krishnadas, I. Rubinstein, Human galanin expresses amphipathic properties that modulate its vasoreactivity in vivo, Peptides 24 (2003) 1373-1380.

[79] A. Banerjee, H. Onyuksel, Human pancreatic polypeptide in a phospholipid based micellar formulation, Pharm.Res. 29 (2012) 1698-1711.

[80] A. Kuzmis, S. B. Lim, E. Desai, E. Jeon, B. Lee, I. Rubinstein, H. Onyuksel, Micellar nanomedicine of human neuropeptide Y, Nanomed.Nanotechnol.Biol.Med. 7 (2011) 464-471.

[81] S. Onoue, A. Matsumoto, Y. Nagano, K. Ohshima, Y. Ohmori, S. Yamada, R. Kimura, T. Yajima, K. Kashimoto, $\alpha$-Helical structure in the C-terminus of vasoactive intestinal peptide: Functional and structural consequences, Eur.J.Pharmacol. 485 (2004) 307-316.

[82] V. Manojlovic, K. Winkler, V. Bunjes, A. Neub, R. Schubert, B. Bugarski, G. Leneweit, Membrane interactions of ternary phospholipid/cholesterol bilayers and encapsulation efficiencies of a RIP II protein, Colloids and Surfaces B: Biointerfaces 64 (2008) 284-296.

[83] F. Hajos, B. Stark, S. Hensler, R. Prassl, W. Mosgoeller, Inhalable liposomal formulation for vasoactive intestinal peptide, Int.J.Pharm. 357 (2008) 286-294.

[84] V. Sethi, H. Onyuksel, I. Rubinstein, Liposomal vasoactive intestinal peptide, in: Methods in Enzymology, Academic Press, pp. 377-95.

[85] J. S. Powell, D. J. Nugent, J. A. Harrison, A. Soni, A. Luk, H. Stass, E. Gorina, Safety and pharmacokinetics of a recombinant factor VIII with pegylated liposomes in severe hemophilia A, J.Thromb.Haemost. 6 (2008) 277-283.

[86] I. Rubinstein, H. Ikezaki, H. Onyuksel, Intratracheal and subcutaneous liposomal VIP normalizes arterial pressure in spontaneously hypertensive hamsters, Int.J.Pharm. 316 (2006) 144-147.

[87] R. H. Müller, S. A. Runge, V. Ravelli, A. F. Thünemann, W. Mehnert, E. B. Souto, Cyclosporine-loaded solid lipid nanoparticles (SLN®): Drug-lipid physicochemical 
interactions and characterization of drug incorporation, Eur.J.Pharmaceutics Biopharmaceutics 68 (2008) 535-544.

[88] A. J. Almeida, E. Souto, Solid lipid nanoparticles as a drug delivery system for peptides and proteins, Adv.Drug Deliv.Rev. 59 (2007) 478-490.

[89] B. Sarmento, S. Martins, D. Ferreira, E. B. Souto, Oral insulin delivery by means of solid lipid nanoparticles, Int.J.Nanomedicine 2 (2007) 743-749.

[90] S. A. Wissing, O. Kayser, R. H. Müller, Solid lipid nanoparticles for parenteral drug delivery, Adv.Drug Deliv.Rev. 56 (2004) 1257-1272.

[91] W. Ge, Y. Li, Z. S. Li, S. H. Zhang, Y. J. Sun, P. Z. Hu, X. M. Wang, Y. Huang, S. Y. Si, X. M. Zhang, Y. F. Sui, The antitumor immune responses induced by nanoemulsion-encapsulated MAGE1-HSP70/SEA complex protein vaccine following peroral administration route, Cancer Immunol.Immunother. 58 (2009) 201-208.

[92] A. S. Pattani, S. D. Mandawgade, V. B. Patravale, Development and comparative anti-microbial evaluation of lipid nanoparticles and nanoemulsion of polymyxin $B$, J.Nanosci Nanotechnol 6 (2006) 2986-2990.

[93] Y. Namiki, T. Namiki, M. Date, K. Yanagihara, M. Yashiro, H. Takahashi, Enhanced photodynamic antitumor effect on gastric cancer by a novel photosensitive stealth liposome, Pharmacol.Res. 50 (2004) 65-76.

[94] J. X. Zhang, C. B. Hansen, T. M. Allen, A. Boey, R. Boch, Lipid-derivatized poly(ethylene glycol) micellar formulations of benzoporphyrin derivatives, J.Controlled Release 86 (2003) 323-338.

[95] I. Skidan, P. Dholakia, V. Torchilin, Photodynamic therapy of experimental B-16 melanoma in mice with tumor-targeted 5,10,15,20-tetraphenylporphin-loaded PEG-PE micelles, J.Drug Target. 16 (2008) 486-493.

[96] L. O. Cinteza, T. Y. Ohulchanskyy, Y. Sahoo, E. J. Bergey, R. K. Pandey, P. N. Prasad, Diacyllipid micelle-based nanocarrier for magnetically guided delivery of drugs in photodynamic therapy, Mol.Pharm. 3 (2006) 415-423.

[97] N. Fomina, J. Sankaranarayanan, A. Almutairi, Photochemical mechanisms of lighttriggered release from nanocarriers, Adv.Drug Deliv.Rev. In Press (2012).

[98] M. E. O'Brien, N. Wigler, M. Inbar, R. Rosso, E. Grischke, A. Santoro, R. Catane, D. G. Kieback, P. Tomczak, S. P. Ackland, F. Orlandi, L. Mellars, L. Alland, C. Tendler, CAELYX Breast Cancer Study Group, Reduced cardiotoxicity and comparable efficacy in a phase III trial of pegylated liposomal doxorubicin $\mathrm{HCl}$ (CAELYX/Doxil) versus conventional doxorubicin for first-line treatment of metastatic breast cancer, Ann.Oncol. 15 (2004) 440-449.

[99] G. Batist, G. Ramakrishnan, C. S. Rao, A. Chandrasekharan, J. Gutheil, T. Guthrie, P. Shah, A. Khojasteh, M. K. Nair, K. Hoelzer, K. Tkaczuk, Y. C. Park, L. W. Lee, Reduced cardiotoxicity and preserved antitumor efficacy of liposome-encapsulated doxorubicin and cyclophosphamide compared with conventional doxorubicin and cyclophosphamide in a randomized, multicenter trial of metastatic breast cancer, J.Clin.Oncol. 19 (2001) 1444-1454.

[100] Etoposide official FDA information side effects and uses, Available from: http://www.drugs.com/pro/etoposide.html. 
[101] M. D. Joshi, R. H. Müller, Lipid nanoparticles for parenteral delivery of actives, Eur.J.Pharmaceutics Biopharmaceutics 71 (2009) 161-172.

[102] C. E. Ashley, E. C. Carnes, G. K. Phillips, D. Padilla, P. N. Durfee, P. A. Brown, T. N. Hanna, J. Liu, B. Phillips, M. B. Carter, N. J. Carroll, X. Jiang, D. R. Dunphy, C. L. Willman, D. N. Petsev, D. G. Evans, A. N. Parikh, B. Chackerian, W. Wharton, D. S. Peabody, C. J. Brinker, The targeted delivery of multicomponent cargos to cancer cells by nanoporous particle-supported lipid bilayers, Nat.Mater. 10 (2011) 389-397.

[103] I. Rubinstein, I. Soos, H. Onyuksel, Intracellular delivery of VIP-grafted sterically stabilized phospholipid mixed nanomicelles in human breast cancer cells, Chem.Biol.Interact. 171 (2008) 190-194.

[104] H. Onyuksel, E. Jeon, I. Rubinstein, Nanomicellar paclitaxel increases cytotoxicity of multidrug resistant breast cancer cells, Cancer Lett. 274 (2009) 327-330.

[105] S. Dagar, A. Krishnadas, I. Rubinstein, M. J. Blend, H. Onyuksel, VIP grafted sterically stabilized liposomes for targeted imaging of breast cancer: In vivo studies, J.Controlled Release 91 (2003) 123-133.

[106] J. F. Lovell, C. S. Jin, E. Huynh, H. Jin, C. Kim, J. L. Rubinstein, W. C. Chan, W. Cao, L. V. Wang, G. Zheng, Porphysome nanovesicles generated by porphyrin bilayers for use as multimodal biophotonic contrast agents, Nat.Mater. 10 (2011) 324-332.

[107] A. Allegra, G. Penna, A. Alonci, V. Rizzo, S. Russo, C. Musolino, Nanoparticles in oncology: The new theragnostic molecules, Anticancer Agents Med.Chem. 11 (2011) 669-686.

[108] E. Gonzalez-Rey, N. Varela, A. Chorny, M. Delgado, Therapeutical approaches of vasoactive intestinal peptide as a pleiotropic immunomodulator, Curr.Pharm.Des. 13 (2007) 1113-1139.

[109] A. Béduneau, P. Saulnier, J. Benoit, Active targeting of brain tumors using nanocarriers, Biomaterials 28 (2007) 4947-4967.

[110] S. M. Demos, S. Dagar, M. Klegerman, A. Nagaraj, D. D. McPherson, H. Onyuksel, In vitro targeting of acoustically reflective immunoliposomes to fibrin under various flow conditions, J.Drug Target. 5 (1998) 507-518.

[111] T. A. Elbayoumi, V. P. Torchilin, Tumor-specific antibody-mediated targeted delivery of doxil® reduces the manifestation of auricular erythema side effect in mice, Int.J.Pharm. 357 (2008) 272-279.

[112] D. Goldstein, O. Gofrit, A. Nyska, S. Benita, Anti-HER2 cationic immunoemulsion as a potential targeted drug delivery system for the treatment of prostate cancer, Cancer Res. 67 (2007) 269-275.

[113] A. Lutterotti, R. Martin, Getting specific: Monoclonal antibodies in multiple sclerosis, The Lancet Neurology 7 (2008) 538-547.

[114] P. L. Myskowski, A. C. Halpern, Cutaneous adverse reactions to therapeutic monoclonal antibodies for cancer, Curr.Allergy Asthma Rep. 8 (2008) 63-68.

[115] R. M. Sawant, J. P. Hurley, S. Salmaso, A. Kale, E. Tolcheva, T. S. Levchenko, V. P. Torchilin, "SMART" drug delivery systems: Double-targeted pH-responsive pharmaceutical nanocarriers, Bioconjug.Chem. 17 (2006) 943-949.

[116] V. Torchilin,Multifunctional and stimuli-sensitive pharmaceutical nanocarriers, Eur.J.Pharmaceutics Biopharmaceutics 71 (2009) 431-444. 
[117] S. Ganta, H. Devalapally, A. Shahiwala, M. Amiji, A review of stimuli-responsive nanocarriers for drug and gene delivery, J.Controlled Release 126 (2008) 187-204.

[118] M. O. Oyewumi, R. A. Yokel, M. Jay, T. Coakley, R. J. Mumper, Comparison of cell uptake, biodistribution and tumor retention of folate-coated and PEG-coated gadolinium nanoparticles in tumor-bearing mice, J.Control.Release 95 (2004) 613-626.

[119] H. Shmeeda, L. Mak, D. Tzemach, P. Astrahan, M. Tarshish, A. Gabizon, Intracellular uptake and intracavitary targeting of folate-conjugated liposomes in a mouse lymphoma model with up-regulated folate receptors, Mol.Cancer.Ther. 5 (2006) 818-824.

[120] Y. Gupta, A. Jain, P. Jain, S. K. Jain, Design and development of folate appended liposomes for enhanced delivery of 5-FU to tumor cells, J.Drug Target. 15 (2007) 231240.

[121] L. A. Pires, R. Hegg, C. J. Valduga, S. R. Graziani, D. G. Rodrigues, R. C. Maranhao, Use of cholesterol-rich nanoparticles that bind to lipoprotein receptors as a vehicle to paclitaxel in the treatment of breast cancer: Pharmacokinetics, tumor uptake and a pilot clinical study, Cancer Chemother.Pharmacol. 63 (2009) 281-287.

[122] J. D. Glickson, S. Lund-Katz, R. Zhou, H. Choi, I. W. Chen, H. Li, I. Corbin, A. V. Popov, W. Cao, L. Song, C. Qi, D. Marotta, D. S. Nelson, J. Chen, B. Chance, G. Zheng, Lipoprotein nanoplatform for targeted delivery of diagnostic and therapeutic agents, Mol.Imaging 7 (2008) 101-110.

[123] X. Guo, F. Cui, Y. Xing, Q. Mei, Z. Zhang, Investigation of a new injectable thermosensitive hydrogel loading solid lipid nanoparticles, Pharmazie 66 (2011) 948952.

[124] J. Szebeni, L. Baranyi, S. Savay, M. Bodo, D. S. Morse, M. Basta, G. L. Stahl, R. Bunger, C. R. Alving, Liposome-induced pulmonary hypertension: Properties and mechanism of a complement-mediated pseudoallergic reaction, Am.J.Physiol.Heart Circ. Physiol. 279 (2000) H1319-28.

[125] P. Aggarwal, J. B. Hall, C. B. McLeland, M. A. Dobrovolskaia, S. E. McNeil, Nanoparticle interaction with plasma proteins as it relates to particle biodistribution, biocompatibility and therapeutic efficacy, Adv.Drug Deliv.Rev. 61 (2009) 428-437.

[126] M. Lundqvist, J. Stigler, G. Elia, I. Lynch, T. Cedervall, K. A. Dawson, Nanoparticle size and surface properties determine the protein corona with possible implications for biological impacts, Proc.Natl.Acad.Sci.U.S.A. 105 (2008) 14265-14270.

[127] A. S. Zahr, C. A. Davis, M. V. Pishko, Macrophage uptake of core-shell nanoparticles surface modified with poly(ethylene glycol), Langmuir 22 (2006) 81788185.

[128] D. Bhadra, S. Bhadra, P. Jain, N. K. Jain, Pegnology: A review of PEG-ylated systems, Pharmazie 57 (2002) 5-29.

[129] Yu, S,S, C. M. Lau, S. N. Thomas, W. G. Jerome, D. J. Maron, J. H. Dickerson, J. A. Hubbell, T. D. Giorgio, Size and charge-dependent non-specific uptake of PEGylated nanoparticles by macrophages, Int.J.Nanomed. 2012 (2012) 799-813.

[130] M. Eugene,Polyethyleneglycols and immunocamouflage of the cells tissues and organs for transplantation, Cell.Mol.Biol.(Noisy-le-grand) 50 (2004) 209-215. 
[131] M. G.,Pegylation: Engineering improved pharmaceuticals for enhanced therapy, Cancer Treat.Rev. 28, Supplement 1 (2002) 13-16.

[132] C. M. Lee, Y. Choi, E. J. Huh, K. Y. Lee, H. C. Song, M. J. Sun, H. J. Jeong, C. S. Cho, H. S. Bom, Polyethylene glycol (PEG) modified 99mTc-HMPAO-liposome for improving blood circulation and biodistribution: The effect of the extent of PEGylation, Cancer Biother.Radiopharm. 20 (2005) 620-628.

[133] J. Rossi, S. Giasson, M. N. Khalid, P. Delmas, C. Allen, J. Leroux, Longcirculating poly(ethylene glycol)-coated emulsions to target solid tumors, Eur.J.Pharmaceutics Biopharmaceutics 67 (2007) 329-338.

[134] J. R. Robinson, V. H. Lee, Controlled drug delivery: Fundamentals and applications, 2nd ed., Marcel Dekker, Inc., New York, USA, 1993.

[135] J. M. Harris, N. E. Martin, M. Modi, Pegylation: A novel process for modifying pharmacokinetics, Clin.Pharmacokinet. 40 (2001) 539-551.

[136] S. M. Moghimi, A. C. Hunter, J. C. Murray, Long-circulating and target-specific nanoparticles: Theory to practice, Pharmacol.Rev. 53 (2001) 283-318.

[137] A. N. Lukyanov, V. P. Torchilin, Micelles from lipid derivatives of water-soluble polymers as delivery systems for poorly soluble drugs, Adv.Drug Deliv.Rev. 56 (2004) 1273-1289.

[138] R. R. Sawant, R. M. Sawant, A. A. Kale, V. P. Torchilin, The architecture of ligand attachment to nanocarriers controls their specific interaction with target cells, J.Drug Target. 16 (2008) 596-600.

[139] R. L. Nation, A. M. Evans, R. W. Milne, Pharmacokinetic drug interactions with phenytoin (part I), Clin.Pharmacokinet. 18 (1990) 37-60.

[140] J. C. McElnay, P. F. D'Arcy, Protein binding displacement interactions and their clinical importance, Drugs 25 (1983) 495-513.

[141] R. Zini, P. Riant, J. Barre, J. P. Tillement, Disease-induced variations in plasma protein levels. implications for drug dosage regimens (part I), Clin.Pharmacokinet. 19 (1990) 147-159.

[142] H. Heiati, R. Tawashi, N. C. Phillips, Solid lipid nanoparticles as drug carriers: II. plasma stability and biodistribution of solid lipid nanoparticles containing the lipophilic prodrug 3'-azido-3'-deoxythymidine palmitate in mice, Int.J.Pharm. 174 (1998) 71-80.

[143] A. H. Sehon, G. M. Lang, Avoiding untoward immune responses to novel gene products, J.Liposome Res. 12 (2002) 199-204.

[144] A. M. Chen, M. D. Scott, Current and future applications of immunological attenuation via pegylation of cells and tissue, BioDrugs 15 (2001) 833-847.

[145] S. Naik, M. Chougule, B. K. Padhi, A. Misra, Development of novel lyophilized mixed micelle amphotericin B formulation for treatment of systemic fungal infection, Curr.Drug Deliv. 2 (2005) 177-184.

\section{Figure and Table Captions with Legends}

Figure 1. Illustrations of various lipid based carriers

Schematic diagrams of (a) unilamellar liposome, (b) PEGylated phospholipid micelle, (c) solid lipid nanoparticles, (d) o/w nanoemulsion, and (e) nanosuspension dispersed in 
aqueous media. Please note that for preparation and stabilization of solid lipid nanoparticles, o/w nanoemulsions and nanosuspensions, other surfactants are quite commonly used instead of phospholipids, which can raise toxicity concerns.

Figure 2. Assessment of cytotoxic potential of SSM on cells.

Percent survival of MCF-7 breast cancer cells when treated with empty SSM (•) as assessed through MTT assay. Values are means \pm SEM; each group, $n=3$. (unpublished result).

Figure 3. Enhancement of duration of activity of secretin in presence of micelles Effects of secretin $(1.0,5.0$, and 10.0nmol) in saline and in SSM on duration of vasodilation in intact hamster cheek pouch. Values are means $\pm S$.E.M.; each group, $n=4$ animals. ${ }^{*} p<0.05$ in comparison to baseline; ${ }^{+} p<0.05$ in comparison to secretin in saline [75]. Reprinted with permission from Elsevier.

Figure 4. Active targeting of VIP through receptor mediated internalization Normalized fluorescence signal in human MCF-7 cells after $2 \mathrm{~h}$ incubation with VIPgrafted, quantum dots-encapsulated sterically stabilized mixed phospholipid micelles (VIP-SSMM-QD) or SSMM-QD in the absence and presence of excess PACAP(6-38) (a) and galanin (b) (each $30 \mu \mathrm{M})$. $\quad \mathrm{p}<0.05$ in comparison to SSMM-QD with excess PACAP(6-38) and galanin, respectively [103]. Reprinted with permission from Elsevier.

Figure 5. Enhanced accumulation of actively targeted liposomes in cancer tissue Accumulation of Tc-99m-HMPAO encapsulating VIP-grafted sterically stabilized liposomes (SSL) and Tc-99m-HMPAO encapsulating SSL in normal breast tissue and breast cancer tissue (each data, $n=5$, mean \pm S.E.M.). ${ }^{*} \mathrm{p}<0.05$ compared to Tc-99mHMPAO encapsulating SSL in breast cancer; \#p<0.05 compared to Tc-99m-HMPAO encapsulating SSL and VIP-SSL in normal breast; ${ }^{\wedge} p<0.05$ compared to Tc-99mHMPAO encapsulating SSL and VIP-SSL in normal breast [105]. Reprinted with permission from Elsevier.

Figure 6. Abrogation of VIP adverse effects when associated with micelles Effects of VIP in micelles ( $\mathbf{a})$ and VIP alone ( $\square$ ) on mean systemic arterial blood pressure in mice [43]. Reprinted with permission from Elsevier.

Table 1. Lipid-based nanocarriers for drug delivery.

Comparison of various lipid based nanocarriers with examples and phase of development. 